\title{
UNA REFLEXIÓN TRASCENDENTAL SOBRE LO DIVINO
}

Jacinto RIVERA DE ROSALES

UNED. Dpto. de Filosofia

\section{Presentación}

La "reflexión" que aqui vamos a llevar a cabo hace referencia a la actividad propia de la filosofia, teniendo en cuenta que es uno de los tipos de reflexión posibles. El modo o método de reflexión que seguiremos es el llamado "transcendental", que elaboraron Kant y el Idealismo alemán, pero siguiendo asimismo mi propio discurso e inspiración. En qué consista este método y cómo lo entiendo se irá viendo en la aplicación concreta que de êl hago a lo largo del articulo.

Aunque también se hablará de Dios, en el título sólo hago mención de lo divino, porque considero que es un término más genérico y a la vez más adecuado a lo que voy a proponer.

El hilo conductor de esta investigación es la definición o comprensión de lo divino como lo originario, el "arjé", como aquello de donde procede y depende la otra realidad, ya sea como causa. como emanación, como padre engendrador, como creador o demiurgo, etc. En esto coincidirian tanto las religiones como las filosofias que afirman la existencia de lo divino, de los dioses o de Dios, e incluso aquéllas que lo niegan y sostienen que Dios ha muerto, que no existe fundamento alguno. Este seria el punto de partida de sus esfuerzos y desarrollos posteriores, tendentes a explicitar qué se está entendiendo por realidad originaria o realidad por antonomasia. Eso es justamente lo que aqui nos tenemos que preguntar: cómo entender lo originario y si hay alguna experiencia que pueda dar contenido a ese concepto.

Dado que hemos de abordar los temas filosóficamente (y no al modo de la ciencia o de la religión o del arte, etc.), a la cuestión de 
cómo entender lo originario hemos de contestar especificando cuál seria su modo de ser. El ser se dice de varias maneras, afirma Aristóteles (Metafisica IV, 2, 1003 a 32), o sea, que "algo es" se dice en diversos sentidos; para Aristóteles, según el acto y la potencia, según lo verdadero y lo falso, según el ser accidental y sobre todo según las diversas categorias (Metafisica VI, 2, 1026 a 33- b 2). Siguiendo a la filosofia kantiana podriamos decir que se dice fundamentalmente de dos, lo que en su propia terminologia se expresa asi: "no hay más que dos clases de conceptos, que dan lugar a muchos principios diferentes de la posibilidad de sus objetos, a saber: los conceptos de la naturaleza y el concepto de la libertad" (Crítica del Juicio, Introducción I).

Por consiguiente, en un primer momento tendremos que preguntarnos si lo originario puede mostrarse en el modo de ser de la naturaleza, como cosa, objeto o substancia absoluta. La respuesta será negativa, pero de paso habremos ganado algo que si se nos aparece, desde nuestra finitud, pasividad y sensibilidad, como originario e irreductible a nuestra acción, y que podemos llamar materia o energia.

En segundo lugar habremos de investigar si lo divino puede tener la forma de ser de la conciencia y la voluntad, si pudiera ser un sujeto infinito. De nuevo la respuesta será: no. Pero tampoco aquí nos iremos de vacio: la libertad, y también la autoconciencia se nos presentan como algo originario (espontaneidad subjetiva) y. por tanto, algo que tendrá que ver con lo divino.

Por último, en la Critica del Juicio Kant aborda el estudio de la naturaleza desde el punto de vista de la libertad: "como si" la naturaleza se organizara según fines propios. Esta sintesis de naturaleza y libertad, sintesis concreta que cada uno de nosotros somos, se nos manifiesta en el sentir, en el sentimiento. Descubrimos que parte de la naturaleza, que algunos objetos (por ejemplo nuestro propio cuerpo) se organizan en una totalidad teleológica, como si se manifestara en ellos una natura naturans, una fuerza configuradora (bildende Kraft), una imaginación productiva (produktive Einbildungskraft) de formas vivas (o bellas) desde la que nos apoyamos y partimos y que serian nuestras raices. Tampoco eso agotará lo divino, pero es indudable que ahí encontraremos material para su comprensión. 
Eso es lo que tendremos que abordar en un cuarto momento. Con los elementos originarios que hemos ido descubriendo nos aventuraremos a decir algo sobre lo divino. Con eso habremos ido contestando también a la segunda pregunta sobre si hay una experiencia de ello, que era todo lo que aqui me proponia.

\section{1.- Dios como Objeto o Substancia absoluta}

Así es como conceptúa lo originario gran parte de la teodicea o teologia natural. Aqui se trata de ver la contradicción y por tanto la imposibilidad transcendental de dicho concepto, y eso a partir de las fuentes (implicadas entre si) desde las que surge:

A.- desde el conocimiento objetivo o ámbito de lo teórico y

B.- desde el deseo. que instaura lo técnico-pragmático. en la medida en que ambas son pensadas o vividas en el ámbito inaugurado por la petición racional de lo incondicionado.

Como he hecho ya una alusión a la historia de la filosofia, antes de entrar en materia será interesante aclarar algo. Los conceptos que manejo aqui (Substancia absoluta, Sujeto infinito, Natura naturans, etc), están tomados desde un punto de vista propiamente sistemático, y no pretenden sin más describir filosofias concretas e históricas, pues eso seria sumamente simplificador. El pensamiento de un filósofo concreto es siempre más complejo, contiene una evolución, elementos distintos e incluso contradictorios, o que pueden ser enfocados desde distintas perspectivas y dar lugar a diversas fecundidades.

\section{A.- Desde el conocimiento objetivo}

El conocimiento objetivo del mundo, tanto el cotidiano como el científico, me permite. en mayor o menor medida. saber cómo funciona y a qué atenerme respecto a la realidad que yo no protagonizo.

Si yo fuera toda la realidad, no seria posible objetivar nada, ni habria mundo. Pero si yo no fuera en alguna medida real zqué interés tendria en preocuparme por la realidad del mundo?. Ni 
siquiera podria realizar la acción ideal de conocerlo. Tampoco habria interés por objetivar el mundo si mi realidad no dependiera, por su finitud, de la realidad del mundo, es decir, si no estuviera en cierta relación real y dinámica con él. Pero tampoco surgiria ese interés si mi realidad dependiera de tal modo que no pudiera hacer nada desde mi y fuera mera marioneta del mundo, si yo no protagonizara en alguna medida mi vida y además tendiera a protagonizarla en la mayor medida posible, es decir, si yo no fuera sujeto y me impusiera la tarea de realizarme como tal.

El conocimiento teórico del mundo parte de esa tarea lesa es su raíz práctico prágmática, su interés) y en concreto la de saber a qué atenerme ante la realidad de mundo de la que dependo y cómo manejar aquella que puedo modificar. Para ello nos esforzamos por (re)construir la trama del mundo, esto es, cómo unas cosas dependen de otras, cómo después de esto viene aquello, cómo haciendo algo consigo lo que deseo, etc. Si las cosas no fueran en absoluto apresables en una trama de interdependencia, es decir, si fueran enteramente independientes y desconectadas entre si, todo seria imprevisible y no habria forma de saber qué hacer, ni de cómo subvenir a mis necesidades.

El interés teórico se dirige, por consiguiente, al establecimiento de una experiencia estructurada, unitaria y coherente, donde todo quede lo más determinado posible, lo más atado. lo más ligado, aunque sea de manera estadistica y con matemáticas de la probabilidad. No se trata, por tanto, de una determinación autónoma y espontánea de las cosas, sino de una determinación heterónoma, una determinación de cada fenómeno por sus relaciones de dependencia respecto a los otros: de su tiempo en relación con los otros fenómenos con los que interactúa, de su espacio mediante su entorno, de su aparición por causas que no son él mismo sino que lo determinan desde fuera, etc. El interés teórico fija su atención metodológicamente en eso, y sólo en la medida en que algo es determinado en relación a lo otro es objetivado, y en la medida en que no lo sea, queda indeterminado, no conocido objetivamente. imprevisible. Recurrir a la autonomia, a la libertad, no es ninguna explicación objetiva, sino que en este ámbito sería metodológicamente considerado como mera ignorancia de las causas.

Ahora bien, sólo llegariamos a superar enteramente nuestra finitud y dependencia del mundo si pudiéramos determinar 
objetivamente toda la realidad. Lo dominariamos todo, entonces. Esa apertura ideal a la totalidad, esa exigencia subjetiva de completud, es lo que Kant denomina "razón", y aqui en concreto en su actividad teórica o razón teórica. Y sin embargo es imposible alcanzar dicha totalidad por el camino de la determinación heterónoma, justamente por ser heterónoma, pues siempre reenvia a otro elemento para poder comprender lo puesto. El proceso sólo se detendria si pudiéramos llegar por ese camino a un elemento incondicionado, o sea, a un objeto absoluto. Pero todo objeto es delimitado y relativo, ninguno puede ser absoluto,

a.-ni en el sentido de estar totalmente absuelto de dependencias respecto a las otras cosas,

b.-ni en el sentido de ser toda la realidad.

a.- Si algo estuviera absuelto de toda dependencia con respecto al mundo entonces no podría ser objetivado, es decir, comprendido objetivamente por nosotros.

En consecuencia, hablar de un Dios como objeto o substancia transcendente al mundo y enteramente independiente de él es una contradicción transcendental, es decir, es una afirmación que entra en contradicción con el modo como la subjetividad contruye la comprensión que da lugar al concepto de objeto, o sea, con sus criterios de objetividad. ¿Cómo hallar lo originario con el hilo conductor de la heteronomia?. El modo de ser de lo divino no puede ser el del objeto porque no cumple con las condiciones o criterios transcendentales con los que determinamos ese modo de ser. siendo asi que el fundamento formal de la objetividad es la idealidad subjetiva transcendental, que configura mi comprensión y determina la dirección de la misma.

No es que la metafísica dogmática (según la llama Kant) sea imposible porque no podamos conocer los objetos suprasensibles (eso es lo que parece hacernos creer a veces Kant sin darse enteramente cuenta de su propia revolución), sino porque la realidad no fenoménica no tiene el modo de ser de la cosa, del objeto. No hay objetos suprasensibles. La expresión kantiana de "las cosas en si" es desafortunada.

b.- Ahora bien, podriamos pensar que, si bien la limitación de nuestras capacidades no nos permite llegar a objetivarlo todo, el 
éxito de nuestro conocimiento científico y técnico nos abren la posibilidad de afirmar que todo, incluso lo que aún no conocemos, está objetivamente determinado y que hemos de avanzar por ese camino, pues fuera de él sólo hay ignorancia de las causas y de los procesos reales. El objeto absoluto no es entonces transcendente, sino que la objetividad es la estructura de toda la realidad, y toda ella representaria un solo objeto. Luego algo divino u originario no existe, o como mucho eso seria la gran máquina del mundo.

Frente a ese determinismo teórico (científico-técnico) cabe decir que la totalidad de lo real como tal no puede ser objetivada nunca, pues para ello tendria que ser relacionada con lo que ella no es y que la destruye en su pretensión de totalidad. La totalidad es sólo la idea reguladora de la razón, pues toda experiencia es una experiencia concreta y remite a otra para su comprensión objetiva: un fenómeno remite a otro como su causa, un tiempo a otro anterior, un espacio concreto a su entorno, etc. en un interminable proceso de relación recíproca. Luego la determinación total no puede ser comprobada por ningún método científico, sino que es una afirmación estrictamente metafísica, como toda afirmación que habla de la totalidad.

Por ejemplo, se dice: no somos libres pues estamos totalmente determinados. Pero esa "total determinación" seria como mucho un programa u objetivo de investigación cientifica. porque en realidad estamos muy lejos de saber de hecho cuáles son concretamente esas determinaciones y cómo funcionan. es decir. estamos muy lejos de la verificación empírica de tal determinación total, y por tanto ésta estaria en fase de hipótesis aún no verificada. Según Kant esa verificación siempre estará en proceso por el carácter continuo (espacio-temporal) del fenómeno y por el carácter inconcluso de toda experiencia. De hecho hoy la ciencia habla de modelos teóricos aproximativos y se está abriendo progresivamente a lo estadístico y a lo que se muestra como caos.

La determinación máxima posible es ciertamente el presupuesto metodológico que da lugar al proyecto científico y técnico. El ideal de la razón teórica seria sin duda la objetivación total porque. siguiendo su interés, sólo se fija en la posibilidad de determinar heterónomamente la realidad. Por eso el sujeto puede olvidar, en ese empeño, la raiz práctico-pragmática del proyecto, el que era una tarea de liberación, y convertir los principios que dirigian y 
regulaban esa tarea en principios que constituyeran ya toda la realidad, incluso a él mismo, cuando en verdad sólo alcanza su superficie, lo fenoménico, y sólo puede afirmarse su realidad en la medida en que haya constancia empírica. El olvido está propiciado por la fascinación que producen tanto la claridad teórica que nos proporciona el concepto científico, la determinación objetiva, como su gran utilidad têcnica y pragmática, el gran poder que nos pone entre las manos.

Pero a causa de ese olvido la subjetividad entra en contradicción transcendental consigo misma: por un lado quiere ser libre. y por otro se piensa heterónomamente determinada. "Contradicción transcendental" significa que la subjetividad, en la construcción de sí. de su comprensión y de su acción o libertad, encuentra en sí misma diversas instancias o exigencias propias que le constituyen y que, por tanto, le son necesarias, pero que, sin embargo, parecen anularse las unas a las otras en un conflicto sin cuartel.

Ese conflicto de intereses sólo puede ser resuelto poniendo limites y estableciendo prioridades. Límites a nuestra libertad. viendo que no es algo transcendente ni omnipotente. sino que se encuentra mediatizada por la objetividad del mundo. Pero también limites a las pretensiones totalizadoras de la razón teórica (un tema central de la Critica de la razón pura). ¿Cómo?: examinando la dialéctica a la que aboca; mostrando que el determinista es un dogmático, pues afirma más de lo que sabe al reificar y objetivar lo que no es sino un principio subjetivo de comprensión y una tarea cuyo proyecto nunca se sabe hasta dónde puede llegar, es decir, descubriendo la idealidad transcendental de fondo de la actividad teórica; viendo que la comprensión objetiva no es la única válida, pues tiene como condición de posibilidad (como raiz y sentido) la comprensión que el sujeto tiene de sí como sujeto y proyecto de libertad $y$, por tanto, que ésta es ontológicamente superior a aquẻlla. Luego el olvido es, en definitiva, un olvido de sí, de las propias raíces de la subjetividad; y la tarea no será ir más allá del sujeto, como proponen los postmodernos (¿quiēn es el que se liberaria entonces?). sino ir más allá de la superficialidad con la que lo habiamos comprendido, es decir, hay que retornar de nuevo sobre la subjetividad, llevar a cabo un mejor análisis de dichas raices, comprender la primacia de lo práctico sobre lo teórico, y actuar desde ahi. 
Conclusión: el ateismo tiene razón cuando sostiene que no existen más objetos que los de este mundo, pero no cuando afirma o en la medida en que afirme que toda la realidad se agota en los objetos del mundo, en el modo de ser de la objetividad.

"Buscamos por todas partes lo incondicionado y sólo encontramos cosas" (Novalis, Blüthenstaub 1). La imposibilidad de hallar una realidad objetiva que colme la petición racional muestra ya la idealidad y la libertad del pensamiento, o sea, de la subjetividad, su superioridad ontológica. Si estuviéramos determinados por el mundo, por la realidad objetiva, ¿cómo podriamos pedir lo que no existe?.

Pero la conciencia es sólo una espontaneidad ideal que proporciona mera posibilidad, no crea el objeto conocido ex nihilo, como por hipótesis lo haria un Dios creador. La existencia del objeto le tiene que venir dada: pasividad, sensibilidad. Si bien la forma del fenómeno tiende a disolverse en meras relaciones heterónomas, en relaciones conceptuales e interpretaciones, los fenómenos u objetos no son meras relaciones formales o ficciones, sino una presencia, una materialidad, una realidad no inventada, algo que existe desde sí (aunque su objetivación corra a cargo del sujeto) con una realidad que el sujeto no protagoniza, que se le resiste y le pone limites, con una realidad con la que él tiene que habérselas en orden a sus fines (no sólo hay interpretaciones -como si éstas fueran los únicos hechos-, sino también hechos reales, si bien éstos sólo son comprendidos interpretándolos). Por esa relación dinámica, real, que establecemos con esa otra realidad, ésta se nos aparece también como fuerza, como energia (según se prefiere hablar hoy).

En consecuencia, esa materialidad, ese realismo al que el sujeto se abre gracias a la idealidad de la conciencia, es para nosotros algo originario, no puesto. Los griegos lo pensaron eterno e increado. No asi Agustin de Hipona y los cristianos en general, pero tuvieron que poner a su base un acto tan mágico e insólito como la creación, que además consiste en la creación de la materia por un espíritu puro. En el s. XII David de Dinant identificó Dios y nous con la materia prima. Algo parecido dijo en el Renacimiento Giordano Bruno en algunos de sus textos. Los materialismos de los siglos XVIII, XIX y $\mathrm{XX}$, hacen partir, aunque de maneras muy diferentes, toda la realidad de la materia o energía, dándole la primacia ontológica. 
Incluso casi todos los movimientos religiosos y espirituales de hoy, del New Age, apuntan a la energia como lo propiamente divino, y explican desde ahi toda la realidad.

Ahora bien, el que sea algo originario y que tengamos por tanto que contar con ello a la hora de elaborar nuestro concepto de lo divino en el punto cuarto, no quiere decir que sea lo único originario o su única manifestación, que todo haya de ser pensado en el modo de ser de la materia o de la energia, o como derivado de ellas. Pero aunque yo defienda lo contrario, tampoco quiero con ello decir que lo otro haya de existtr fuera de la materia, transcendente, sin mundo y sin energia, retornando a lo que ya he criticado como una cosificación de lo que no es cosa, pues lo pensariamos entonces con respecto al mundo con la exterioridad que una cosa mantiene respecto a otra, por ejemplo el boligrafo respecto a la ventana.

Por esa originariedad de la materia-energia, por nuestra pasividad frente a la materialidad objetiva, no es válido el argumento ontológico sobre la existencia de Dios, el cual pretende probarla partiendo de su esencia. Es un argumento que no tiene en cuenta que nuestra espontaneidad cognoscitiva es meramente ideal, o sea, que no tiene en cuenta la diferencia transcendental entre posibilidad y existencia, dos categorias modales distintas. Al menos no se puede sacar del concepto una existencia objetiva. Otra cosa será ver si como exigencia subjetiva no apunta también a algo divino. En efecto, Dios-cosa, el Dios Objeto absoluto, se nos muestra a la postre como una exigencia racional, como exigencia profunda de la subjetividad, que ningún objeto real puede colmar; es decir, se nos presenta como querer y no como cosa, como exigencia subjetiva. Yendo más allá del modo de ser de la cosa, el sujeto se nos manifiesta como idealidad transcendental (conciencia) y como querer, como deseo y voluntad. Sigamos ahora ese camino abierto.

\section{B.- Desde el deseo}

Pasamos del ámbito teórico al deseo. Pero el resultado será parecido. Comencemos diciendo que al sujeto no sólo se le aparece 
como originario la materialidad, sino que también él se pone a sí mismo como algo originario.

Que él se pone y se comprende así, se manifiesta en el concepto de finalidad: el sujeto se pone como fin y pone todo lo demás como medio para sus fines. Su existencia y el desarrollo de la misma ocupa para él el centro de la realidad, alrededor del cual procura que gire la otra realidad. Y lo procura por los distintos medios a su alcance: mediante la técnica y la manipulación. la fuerza o la persuasión, la amenaza o la seducción, el arrojo o la prudencia, el desplante o el halago, la hipocresia o la sinceridad, la plegaria o el trabajo, lo bueno y lo malo, etc. Todo puede ser utilizado para esa "voluntad de poder"; lo cual no quiere decir que sólo pueda ser utilizado para eso ni que esa utilización sea sin más moralmente rechazable.

Pero el concepto de fin no es sólo conciencia de originariedad sino también de finitud y mundo. Si fuéramos infinitos no tendriamos que proponernos alcanzar algo que no tuviéramos. Si el mundo no fuera real, si no lo reconociéramos como real, no saldriamos a buscar en él lo que nos falta. Si no hubiera límite y frustración, por qué ibamos a aceptar una realidad fuera de la nuestra que no protagonizáramos.

Esa dualidad de ser originarios y finitos es lo que se manifiesta en el deseo y en la acción técnico-pragmática que él engendra. Por nuestra finitud dependemos del mundo, de realidades que no somos y a las que nos tenemos que acomodar. Pero al ponernos como originarios, al querer que el sentido de nuestra acción parta de nuestra libertad y sus fines, procuramos que esa dependencia sea positiva e incluso que se invierta su signo, que sea yo quien la domine o controle, que yo sea sujeto y todo lo demás objeto para mi, objeto usable. comestible, bebible, de abrigo y cobijo, de satisfacción sexual, etc. Si consigo que el mundo responda a mis deseos, seré feliz. Para ello contamos primordialmente con el conocimiento objetivante anteriormente descrito, de modo que encontramos en el deseo (en el querer en general) su raíz, el interés que lo mueve.

En la finalidad técnico-pragmática el sujeto acepta la realidad del mundo (de la materia o energia) como algo originario que se le impone, pero procura rebajarla ontológicamente al nivel del puro medio. Y eso no ocurre sólo con el hombre, sino con todos los seres 
organizados. Fueron los seres orgánicos los que crearon la bioesfera. Tanto las plantas, como sobre todo los animales organizan también su entorno. Pero en el hombre se da un salto cualitativo: su entorno carece de límites, mejor dicho, su horizonte ideal, de comprensión, se abre a un espacio y un tiempo sin limites, y a ilimitadas posibilidades de relación gracias a la idealidad materializada en el lenguaje. A ese salto lo denominamos "razón". Con ello el sujeto toma una conciencia más plena de si contraponiéndose a un mundo como totalidad, al objeto en cuanto objeto.

Igualmente ilimitada se hace la necesidad de su deseo, no sólo en el espacio: dominar todo el mundo, sino también en el tiempo, con lo cual se le aparece su muerte como finitud infranqueable, y nace en él el deseo de inmortalidad. Ningún objeto del mundo (todos limitados) puede colmar ese deseo ya ilimitado. Ni siquiera el dinero que en su aspecto ideal (de convención) podria llegar a representar la posesión de todos los objetos del mundo o al menos de muchos de ellos.

Sólo el otro deseo, el deseo de otra persona, se presenta como igualmente ilimitado. Nace con ello una dialéctica, una lucha de poder (como en la dialéctica hegeliana del amo y del esclavo), pues cada uno de ellos intenta que el otro, que el deseo del otro, sea una cosa, un puro medio para los propios fines. Es una lucha o bien una relación simbótica que puede alcanzar altas cotas de refinamiento, de seducción, de sado-masoquismo, de esclavitud, etc., cuyas posibilidades son o una prudente limitación e inhibición, o la pasión y la muerte. Pero en ninguno de los dos casos consigue lo que pretendia: la felicidad completa en brazos del objeto absoluto. Y esto no sólo por la azarosa posesión del otro, o por el dolor debido a la inevitable inhibición que nos libere de la muerte (¿quién puede ir por la vida totalmente desinhibido?: "el malestar de la cultura"), sino sobre todo porque el otro no es sólo un objeto y menos aún un objeto absoluto (mala comprensión ontológica), y porque al no tomar al otro como otro, como independiente y partiendo de si, como fin en si mismo y algo originario, tampoco logro (en el espejo del otrol comprenderme a la postre enteramente a mí mismo como realidad originaria, realidad que ha de partir de sí, sino como dependiendo del otro (mala búsqueda de si), contradicción transcendental que va minando necesariamente la construcción de nuestra propia subjetividad. La libertad, la originariedad, se ha de 
pagar con el precio de una soledad (metafisica) frente al mundo y a los otros que se manifiesta, por ejemplo, en la propia resposabilidad ante nuestras acciones. Este paso se da cuando se comprende que el proyecto de fusión con los otros es irrealizable.

Se puede producir entonces la nostalgia de un Objeto absoluto transcendente, de la unión total con $\mathrm{El}$, ya sea antes del nacimiento o después de la muerte, o en un momento de plenitud mistica (o tal vez la nostalgia del seno materno). "¿Qué es, por tanto, lo que nos grita esa avidez y esa impotencia, sino que ha habido en otro tiempo en el hombre una verdadera felicidad, de la que ahora no le queda sino la marca y la huella completamente vacia, que trata inútilmente de colmar con todo lo que le rodea, buscando de las cosas ausentes la ayuda que no obtiene de las presentes, siendo asi que todas son incapaces de ello, porque el abismo infinito sólo puede ser colmado por un objeto infinito e inmutable, es decir, por Dios mismo?" (Pascal, Pensées 148 ó 425; el subrayado es mío). Un Objeto infinito e inmutable colmando mi deseo ilimitado de felicidad. Ese es el "cielo". la transcendencia cósica (del "más allá", al modo de la exterioridad de las cosas) propia del deseo, el ideal del deseo ilimitado. Unidos a un Objeto absoluto habriamos solventado todos los problemas de la finitud, todas nuestras carencias y la misma muerte.

Pero con ello también habriamos entrado en contradicción transcendental con nosotros mismos:

19.- Ese objeto es puesto como absoluto y sin embargo a la vez como relativo. Como absoluto, pues sólo entonces colmaria el deseo infinito. Como relativo, pues es buscado en cuanto colmando ese deseo.

El deseo busca lo absoluto entre los objetos, porque le da miedo la finitud, la separación o soledad, la carencia y la muerte. Pero al buscarlo como objeto. lo busca como medio para su fin, es decir, se pone a si mismo como originario, y al objeto como relativo, a su medida. Por un lado, debido a la finitud nuestra y del mundo, se piensa al objeto cósicamente transcendente; pero como el sujeto no puede dejar de ponerse de forma originaria, entonces aquella transcendencia se reintegra en esa origariedad y se la pone en cuanto colmando sus necesidades. ¿Para qué serviria un Dios que no nos hiciera feliz, que no nos asegurara la inmortalidad? 
(Veremos que lo divino no es sólo posibilidad de felicidad, sino también de noche y de muerte). Aquí nacen las religiones mercantiles, o los aspectos mercantiles de todas o casi todas las religiones, la compra-venta de beneficios divinos mediante diversos actos, ya sea de beneficios en este mundo o en el otro. Y aqui surge también la casta de los sacerdotes dominadores del pueblo debido a su mediación, etc.

Por tanto, es el mismo deseo el que quiere, necesita y busca que ese objeto sea a la vez absoluto y relativo, contradiciéndose a si mismo, revelándose como un querer, como una subjetividad, que no ha llegado a una plena conciencia de si. De ahí parten las críticas a la religión y a lo divino por ejemplo de Marx (la esperanza-opio de los oprimidos respecto a un más allá feliz, que es protesta pero a la vez quita la posibilidad de una acción eficaz y revolucionaria), de Nietzsche (intrumento de poder y de venganza de los débiles unidos contra los fuertes) y de Freud (el deseo infantil de protección frente a la dureza de la vida), criticas que, por otra parte, retoman a su manera ideas repetidas a lo largo de la historia del pensamiento.

29.- Frente a un Objeto absoluto desapareceria la subjetividad pues dejariamos de ser libres, atrahidos irrestiblemente por El como por un imán. Convertidos en marionetas (Kant, Critica de la razón práctica V, 147), dejariamos de actuar y seriamos totalmente pasivos, pues al tenerlo todo no necesitariamos seguir actuando.

Más aún, sì lo otro es un Objeto absoluto, entonces protagoniza toda la realidad, y el sujeto desaparece carente de espacio ontológico. Por eso, dicho Objeto absoluto sólo podria ser encontrado detrás de la muerte; desaparecida la finitud, desaparece también el mundo, pues los dos constituyen aspectos inseparables de un mismo acto en la construcción de la subjetividad: mi finitud implica mundo y a la inversa.

Se quiso eliminar la finitud y con ello se eliminó la misma subjetividad, pues la finitud es un momento esencial de la subjetividad, una de sus condiciones de posibilidad: sólo siendo finito puedo contraponerme a lo otro y tomar conciencia de mi (conciencia requiere contraposición). ¿Cómo contraponerme y distinguirme de lo absoluto?. En él sólo cabe disolverse. 
Pero llegariamos a lo mismo (al fustrado intento de eliminar la finitud) si quisiéramos eliminar el deseo; la cuestión no es eliminarlo. sino clarificarlo, ponerlo en su sitio.

Conclusión: el deseo ilimitado ha comprendido bien que ningún objeto del mundo es lo divino, lo origininario, pero se equivoca cuando sigue buscándolo como objeto, aunque sea como Objeto absoluto transcendente. Lo divino no puede alcanzarse en la forma de ser del objeto, ni como objeto teórico, pues es heteronomia, ni como objeto del deseo, pues seria un medio y no un fin en si mismo. Ambas cosas están ligadas entre sí, pues el conocimiento objetivante parte del querer dominar, y ese querer se objetiva como deseo concreto gracias a dicho conocimiento objetivante.

Lo divino no puede alcanzarse como objeto. ¿Podremos alcanzarlo como sujeto?

\section{2.- Dios como Sujeto infinito}

Nos hemos asomado ya a la originariedad propia del sujeto. Primeramente en cuanto conciencia-autoconciencia, pues su idealidad transcendental es ilimitada y sobrepasa todo lo dado, y además (podemos añadir) sólo partiendo de si puede el sujeto como autoconciencia relacionar consigo mismo sus conocimientos y pensamientos y considerarlos suyos. Pero también hemos hecho referencia a su originariedad en cuanto acción real mediante el concepto de fin. Esa conciencia de su originariedad la alcanza el sujeto más plenamente en la conciencia moral; en ella su ser se le muestra como deber ser, como tarea, como responsabilidad de su propia libertad.

Con esos elementos podriamos construir (y de hecho se ha elaborado) un concepto de Dios en cuanto Sujeto inteligente y racional, libre y moral. Pero mientras que nuestra inteligencia y nuestra acción libre se encuentran mediatizadas por el mundo, debido a nuestra finitud, las de Dios serian creadoras de toda otra realidad, del mundo y de nosotros mismos. Por ello podria asegurarnos la felicidad y la justicia. como un Dios Padre vigilante y 
providente, que impone la moral y le confiere valores absolutos, estableciendo con seguridad lo que hemos de hacer y ser. El seria también el amor que me acoge, gracias al cual no estoy abandonado, arrojado; la estirpe inacabable, la memoria eterna que no deja que caiga en el olvido, en la insignificancia del casi no haber sido. El seria el gran libro donde todo se registra para que no caigamos en la nada (ser realmente sería ser siempre, como la idea en Platón), el que hace que nuestra vida no sea como un soplo en el infinito espacio-temporal, que seamos alguien para Alguien y así seamos algo, que haya Alguien que tenga en cuenta nuestros actos y esfuerzos, la justicia. „Pesa tanto la levedad de nuestro ser, el no ser importantes siendo originarios, el dolor, la soledad de la libertad, de la responsabilidad y de la muerte!

Pero ese concepto de Dios encierra asimismo diversas contradicciones desde el punto de vista transcendental.

19.- Ese Dios no podria ser pensado como Sujeto, ni como un TU según lo hace cierta filosofia dialógica (por ejemplo Martin Buber).

En efecto, el acto de libertad moral por la cual un sujeto se constituye plenamente como sujeto y se hace responsable de sí, sólo es posible dentro del ámbito de la intersubjetividad. Sólo ante el otro, en el espejo del otro, me comprendo a mí mismo como un otro entre otros; sólo respetando al otro como algo realmente distinto de mí, cuya existencia no la pongo yo sino que parte de él y no es un puro medio mio, sólo en esa distancia y contraposición práctica y real tomo plena conciencia de mi como sujeto distinto. también libre e independiente. $Y$ esto es algo que evidentemente no podría hacer un Dios omnipotente, pues de El dependeria enteramente todo lo demás, y por tanto, no podria construirse como sujeto.

$2^{2}$.- Un entendimiento que pueda crear materialmente su objeto nos es inconcebible.

Nuestro entendimiento, dice Kant, es discursivo, no intuitivo. pues nuestra espontaneidad cognoscitiva es ideal, formal, desde su primer principio: la apercepción transcendental, de modo que necesita de algo dado para conocer objetivamente. Justo en eso radica la diferencia entre lo posible o pensable (las formas transcen- 
dentales) y lo existente u objetivamente real (el objeto), y gracias a esa contraposición (esto es lo importante) los distinguimos entre si y alcanzamos conciencia de ello: conciencia del objeto como objetivo, como real, distinto de lo posible o meramente subjetivo, y conciencia de lo posible o subjetivo, aquello con lo que se identifica el sujeto. Gracias a eso, éste se contrapone al objeto y alcanza una conciencia reflexiva de sí, de ser inteligencia pensante. Sólo entonces hay conocimiento, pues conocer es distinguir.

Nada de esto podria hacer un entendimiento infinito, intuyente, pues el objeto es su mismo acto de intuir y no habria la separación real (y no meramente ideal) necesaria para distinguirlo y distinguirse. Un conocimiento objetivo necesita limites, distinción. El objeto ha de ser distinto de mi realidad, me ha de ser dado, aunque en el ilimitado ámbito ideal de $\mathrm{mi}$ conocimiento. El objeto es objeto porque exhibe una realidad que yo no protagonizo. lo que no ocurriria en la supuesta intuición intelectual, en la creación ex nihilo. Pero si no hay distinción, no hay tampoco conocimiento de si, luego esa fuerza creadora no podria ser sujeto, entendimiento; todo lo más seria una fuerza que ocupara toda la realidad como un Objeto absoluto. Para ser sujeto es preciso una finitud real, una distinción real de sí frente a la otra realidad que no se protagoniza. Una distinción de si como sujeto frente a los objetos, a la materia en general, y de si como individuo o acto individual frente a los demás sujetos. Además, como veremos, esta finitud se ha de concretar en un cuerpo orgánico y vivo.

Lo infinito en acto sólo puede ser Objeto absoluto, no sujeto. Pero si al inicio ponemos lo infinito en acto, él ocuparia toda la realidad y no quedaria espacio para lo finito. Ahora bien, como es seguro que existe lo finito, lo infinito es sólo una idea nacida de la ilimitación ideal del pensar y del querer. La afirmación de la existencia objetiva (no meramente ideal) de algo infinito sólo origina contradicciones. Una infinitud real lo sería todo y haria incomprensible cualquier finitud real, pero ésta existe. Para comprender mi finitud no es preciso poner una infinitud en acto, como piensa por ejemplo Descartes, sino una ilimitación ideal (conciencia) que sobrepase la realidad que yo protagonizo, conozca la otra realidad y objetive los limites. No se da lo infinito, sino sólo un proceso ideal sin límites (Aristóteles). Podemos decir que una fuerza sobrepasa toda nuestra capacidad de medición, pero para afirmarla infinita 
tendriamos que haberla medido como tal, lo cual es contradictorio: querer medir lo que pensamos que está o ponemos como estando más allá de toda medida.

39.- En tercer lugar, ese Dios omnipotente, omnisciente y sumamente bueno, requerido normalmente como solución al dolor, las miserias y la injusticia del mundo, está en franca contradicción con eso mismo, pues, o no ha podido hacer un mundo mejor, o no ha sabido o no ha querido.

Ante esta objeción, que dio lugar a la Teodicea (defensa de Dios) de Leibniz, se suele contestar que nuestra corta visión no alcanza a ver el plan total divino, el cual sabe sacar bien del mal y escribir derecho con lineas torcidas (Santa Teresa de Avila). Pero esto, que con otra interpretación que no recurra al teísmo puede constituir una gran sabiduria, en nuestro presupuesto no resuelve el problema, sino que se io traslada de los fines a los medios: Dios podrá tener unos fines maravillosos, pero o no puede alcanzar esos mismos fines con mejores medios. o no sabe o no quiere. En verdad, ante el mal en el mundo no se puede concluir la existencia de un Dios omnipotente, omnisciente y sumamente bueno, sino su ausencia, o todo lo más el deseo de que lo hubiera: isi Dios existiera, esto no pasaria!

Esta contradicción entre el presupuesto del que se parte (el dolor y la injusticia) y lo que se postula (un Dios omnipotente, omnisciente y santol surge de nuevo por querer solventar la finitud de un plumazo. Si al inicio ponemos una realidad perfecta ¿cómo podrá surgir lo imperfecto? No tendria sentido. Sin embargo, ante esta objeción, el creyente puede contestar que Dios, por su grandeza, está más allá de nuestra comprensión, de nuestra razón y de nuestra moral, o incluso que, como autor y dador de todo, está por encima de toda reclamación. del mismo modo que sucede con un regalo, máxime cuando no conocemos sus designios. ¿Cómo nos atreveriamos a juzgar lo que ignoramos? (Libro de Job, XXXVIIIss). "¡Oh hombre! Pero ¿quién eres tú para pedir cuentas a Dios? ¿Acaso la pieza de barro dirá a quien la modeló: por qué me hiciste así? O ¿es que el alfarero no es dueño de hacer de una misma masa unas vasijas para usos nobles y otras para usos despreciables?" (S. Pablo. Epistola a los romanos IX, 18-21). Como soberano absoluto, 
Dios podria hacer lo que le viniera en gana. Por eso la verdadera antinomia se entabla sobre todo entre Dios y la libertad humana.

$4^{\circ}$. - En efecto, ese Dios creador, omnipotente, entra en contradicción con la libertad humana. Por eso, aunque centrados más en el tema de la Gracia que en el de la creación, los reformadores renacentistas optaron por la predeterminación, siguiendo la doctrina de Agustin de Hipona en su disputa contra Pelagio.

La contradicción no se da propiamente entre la omnisciencia divina y la libertad humana. pues aunque Dios sepa desde toda la eternidad lo que voy a hacer, seria yo quien lo hiciera. La imposible conciliación se da entre la omnipotencia creadora (jex nihilo! eso se ha que pensar a fondo, y normalmente no se hace) de Dios y la libertad como pretensión de acto espontáneo: si todo procede de Dios, ¿qué puede proceder de mí? ¿cómo puedo ser yo responsable de mis actos? El "yo" carece de espacio ontológico y es Dios quien actúa en la forma de "mi".

A esta objeción se suele responder:

$1^{\circ}$. Que Dios me da la libertad, como un rey concede favores a sus súbditos, jcomo si la libertad tuviera el modo de ser de la cosa, y fuera posible darla o tomarla!. La libertad constitutiva de la subjetividad no se tiene, se es, pues el sujeto no es una substancia aparte de su libertad que pueda tener ésta o no tenerla como se tiene un color u otro, sino que es su libertad (aunque no es sólo libertad), y eso no en el modo de ser de la exterioridad propia del tener.

Además, siendo Dios toda la potencia, no podria crearme y dejarme ahi, sino que habria de conservarme, de modo que yo no seria sino esa potencia divina que se otorgaria a si misma la capacidad de ser libre (algo también dificilmente comprensible), pero no seria yo en cuanto ser autónomo. Yo no preexisto ni antes ni después del acto que me crea como para ser capaz de recibir, como si ocurre con el súbdito en relación a su rey. No habria un algo independiente de Dios que pudiera recibir. 
$2^{2}$. Más filosófica me parece una segunda posible respuesta: Dios nos hace libres, pues Dios es tan omnipotente que es capaz de crearme libre.

Pero eso, de nuevo, es un concepto transcendentalmente contradictorio. La creación está pensada según el concepto de causa, de causa total, y la causalidad es una categoria objetiva que liga objeto con objeto desde la heteronomia, distinguiéndolos, y por tanto causa total significaria determinación heterónoma total, mientras que la libertad es autonomia, acción incondicionada de mi voluntad independiente de la voluntad de otro. La relación del hombre con lo divino ha de ser pensada de modo diferente.

Conclusión: el teismo es transcendentalmente insostenible. Ha captado bien que el pensar y la acción libre y responsable son originarios, pero se equivoca cuando los piensa como acciones transcendentes, hipostasiándolos en un sujeto imposible lo al menos sostener la existencia de tal Sujeto infinito seria metafisica-ficción). Por tanto, tampoco aqui nos vamos de vacio. Cuando construyamos el concepto de lo divino no podremos olvidar ni la acción libre ni el pensar.

\section{3.- Lo divino como natura naturans o imaginación productiva}

Veiamos que "algo es" se dice de varias maneras. La libertad es, pero no es una cosa, no es en el modo de ser del objeto. No es un objeto más del mundo, pues es autonomia y no heteronomia. Pero tampoco es un objeto transcendente, de otro mundo (como se la piensa por ejemplo en el concepto de "alma inmortal"), no es algo separado de este mundo como una mesa está separada espacialmente de otra, algo separado que pudiera ser sin mundo, como una mesa puede ser aunque la otra no exista. La libertad no es una cosa, ni inmanente ni transcendente, sino una acción transcendental que, partiendo de sí, ha de realizarse en el mundo configurándolo según sus necesidades. Ese es el contenido de la conciencia moral. 
Por consiguiente, para que la libertad se realice, ha de ser posible el tránsito de la libertad a la naturaleza, de la finalidad al mecanismo, es decir, ha de ser posible un punto de unión. El punto de vista que los distingue es un punto de vista analítico, necesario para darse reflexivamente cuenta de los distintos momentos que configuran la realidad, de que ésta no es un totum revolutum, ni algo monocorde. Pero veiamos también que en la realidad no están separados como lo está un objeto de otro, sino sintéticamente unidos.

Ahora nos hemos de colocar en el punto de vista sintético, el de la unión, que es el punto de vista del hombre real y concreto (sintesis de ambas), del hombre que vive y actúa. La unión la vivimos. la sentimos, la comprendemos en la acción misma; en ella yo sé que puedo proponerme algo, por ejemplo escribir, y lograr hacer mundo ese propósito, llevarlo a cabo en el terreno de las causas mecánicas, y porque lo sé. me pongo en marcha. Sé que no soy libertad y naturaleza en la forma de una identidad cósica o analítica, ya dada, pues no confundo mis ideas y mi querer con los movimientos de mi cuerpo, ni identifico mis fantasias con la trama mecánica del mundo (en ese caso no habria ya necesidad de actuar. de esforzarse para que se dé un proceso de identificación), a no ser que me haya vuelto loco, pero entonces se produce una progresiva desintegración de la propia subjetividad. En la acción sé que soy finalidad y mecanismo sintéticamente, es decir diferenciadamente, de modo que su unión representa una tarea, un esfuerzo, una acción, con posibilidad de éxito y también de fracaso. En caso contrario mi vida, mi acción. la subjetividad en general, seria imposible.

Pero ahora, haciendo filosofia, no se trata de actuar sino de reflexionar, y la reflexión tiende (cuando no es meditación) a colocarse en el punto de vista analítico, a repasar uno por uno los múltiples elementos que configuran la realidad mediante la mera idealidad conceptual, mediante meros conceptos, haciendo abstracción del sentír (que es la conciencia primaria que tenemos de esa sintesis, de nuestro estar en el mundo) y de la imaginación productiva sintetizadora. Por eso, apenas se tematiza reflexivamente la unión sintética de libertad y naturaleza, ésta se nos presenta ya desdoblada y derivada, no en el momento mismo de la unión. En el 
ámbito de la libertad aparece como concepto de fin, en el de la naturaleza, como seres orgánicos vivos.Veámoslo.

19.- Desde el ámbito de la libertad y de la conciencia, la unión muestra sus huellas en el mismo concepto de fin.

En efecto, un concepto es ya un momento posterior, de reflexión sobre una acción previa y se apoya necesariamente en ella. En el concepto se aisla la regla que se ha seguido en la acción y la atención se fija en la regla en cuanto regla, abstraida de su funcionar en la acción concreta. Primero ha de tener lugar la acción y sólo después podemos reflexionar sobre ella, sobre su regla configuradora, aunque posteriormente gracias a esa reflexión pueda venir otra acción que sea además reflexivamente dirigida por dicha regla ya conceptuada. Pues bien, el concepto de fin constituye el estadio reflexivo de ese tránsito entre libertad y naturaleza. de su unión sintética en la acción subjetiva, en el sentido de que es la conciencia reflexiva que tenemos de que, en alguna medida, hemos podido llevar a cabo en el mundo nuestros deseos. Luego si no hubiera habido ningún tránsito o unión sintética prerreflexiva no hubiera podido aparecer en el conciencia el concepto de fin.

Esa unión sintética prerreflexiva, preconceptual, es lo que aparece en la conciencia como "sintesis de la imaginación transcendental productiva", según denominación kantiana, sólo tras un análisis transcendental. Se trata de la capacidad subjetiva de crear figuras en lo múltiple, de configurar lo diverso, de dar forma y sentido a lo que parecía presentarse de modo caótico. En la Crítica de la razón pura se nos presenta la imaginación transcendental productiva como la originaria acclón de articular (interpretar) nuestra finitud y el mundo en una trama de objetos concretos. El conocimiento objetivo es primariamente una acción imaginativa. aunque esto lo hemos olvidado debido a la costumbre, a lo temprano del acto, al refuerzo emotivo de la educación y de la integración en una intersubjetividad, etc. Para recuperarlo es preciso un análisis transcendental. Entre la Estética y la Lógica transcendentales, Kant deberia haber insertado su descubrimiento de dicha acción imaginativa en una Poiética transcendental.

En un momento más cercano a nuestra conciencia reflexiva (y por tanto nos damos cuenta de ello más fácilmente), esa imaginación productiva aparece como fundamento de la experiencia 
estética, sobre todo de la acción configuradora del genio artistico, estudiada en la Critica del Juicio. Valga este breve apunte para hacer ver que la subjetividad es fundamentalmente una tarea de sintesis, de aunar las distintas instancias (a veces excluyentes) que nos constituyen, que nos requieren, a las que tenemos que prestar atención. Es decir, la subjetividad es fundamentalmente una tarea imaginativa, de imaginación productiva. creadora de formas y sentido, "poiética" en el sentido más genérico de la palabra.

29.- La unión entre espontaneidad (autonomia) y naturaleza se manifiesta también en el lado de esta última, de la naturaleza, fundamentalmente en la forma de seres vivos, orgánicos y que se organizan a sí mismos. A partir de ellos y del concepto de finalidad se puede elaborar otra comprensión de la naturaleza, no meramente mecánica y heterónoma. sino de una naturaleza que se configura y se organiza a sí misma.

Dado que los seres vivos son objetos de la naturaleza, pueden ser estudiados científicamente desde un punto de vista enteramente mecánico. Pero si tenemos en cuenta lo ya estudiado, a saber, $1^{\circ}$ la limitación ontológica de ese punto de vista mecánico, $2^{\circ}$ la irreductibilidad material del mundo a las formas subjetivas teóricas, $3^{\circ}$ la reducción ontológica que da lugar al proyecto de la ciencia moderna, 4* la necesidad transcendental de que la espontaneidad o libertad pueda configurar el mundo según sus fines, $5^{\circ}$ el análisis (que Kant lleva a cabo en los \$§ 64-66 de la Crítica del Juicio) según el cual, si la finalidad se hace naturaleza, ha de aparecer como un cuerpo organizado vivo, $6^{\circ}$ el hecho de que éstos se dan (en la forma de plantas, animales y hombres), más aún, $7^{\circ}$ el hecho de que mis proyectos, mi finalidad práctico-pragmático-técnica, logra hacerse mundo mediante los movimientos de un cuerpo vivo altamente organizado, es decir, por medio de mi cuerpo, entonces podemos concluir que tenemos fundamentos suficientes para afirmar la finalidad real en la naturaleza, y no sólo "como si" a la manera de Kant.

Y lo podemos afirmar si pensamos dicha finalidad no al modo de nuestra finalidad reflexiva (la única que parece aceptar Kant). Esta se apoya en conceptos, es decir, en la idealidad del pensamiento abstrahída de las acciones concretas gracias a la materialidad del lenguaje, lo que hace posible la distancia respecto a la 
acción, reflexionar sin actuar y que dicha reflexión o concepto guie después una acción concreta. A eso no llega la naturaleza. Su subjetividad y conciencia ha de ser pensada al modo de la sintesis prerreflexiva de la imaginación transcendental productiva, que es una con su propio acto y no anterior a él, aunque ya los animales superiores son capaces de urdir complicadas estratagemas, incluso en grupo, y llevarlas después a cabo.

Según esta perspectiva podemos afirmar que la naturaleza no es sólo una fuerza motriz, mecánica, sino también una fuerza configuradora capaz de propagarse y engendrarse leine sich fortpflanzende bildende Kraft dice Kant), de autonomia configuradora, capaz de aunar en una figura orgánica elementos diversos y contrarios, como una produktive Einbildungskraft, una imaginación realmente productiva de organización y de formas vivas.

Es importante darse cuenta de que aquí el mecanismo y los objetos producidos sirven de trampolin para nuevos productos. Por ejemplo, no es la especie menos organizada la que da lugar a otra más evolucionada, sino que la misma fuerza organizadora que dio lugar a la primera da lugar a la segunda apoyándose en la anterior (pues no es una acción inmanente ni transcendente, sino transcendental); ni son los padres los que configuran al hijo, sino que ellos sirven de base para que el hijo se configure a sí mismo, según corresponde a la autonomia del ser vivo. Empleando terminologia spinozista podemos decir que los objetos son natura naturata, mientras que esa fuerza configuradora seria la natura naturans, pero que ya no actúa more geométrico sino anâlogamente a la subjetividad, como "un yo dormido" (Schelling).

Ella es la que configura nuestro cuerpo, que es unión de mecanismo y espontaneidad. Ella es el trampolin del que partimos. la parte hundida del iceberg en la que se apoya nuestra conciencia y acciones reflexivas, la que nos conecta con la tierra y el sentir como conciencia originaria prerreflexiva. Ella representa nuestras raices, $\tan$ profundas que el cumplimiento de sus propósitos (comer, beber, hacer el acto sexual, respirar, moverse, etc) constituye nuestra mayor fuente de placer y felicidad, de plenitud, o en su defecto nuestra mayor tortura, porque no se trata de una finalidad formulada por el individuo, como ocurre con la reflexiva, sino de una finalidad en la que el individuo mismo es formulado. $Y$ es formulado dentro de una comunidad sincrónica y diacrónica (pues 
la subjetividad no sólo es intersubjetiva en sus aspectos más racionales: en el lenguaje, en el diálogo, en la ciencia, etc., sino también en sus aspectos más primarios, como lo vemos claramente por ejemplo en la sexualidad y en la crianza), y lo es con poderosos lazos de amor y odio, o sea, por medio el sentir en cuanto comprensión originarla de nuestro ser en el mundo.

No puede extrañarnos, por tanto, que ella haya sido la primera en ser divinizada en la forma dioses como fuerzas antropomórficas de la naturaleza, o de animales en la forma de totem. Pues bien, si la reflexión se fija en la pluralidad de sus manifestaciones, da lugar al politeísmo, y si se fija en la unidad, al panteismo.

El politeismo ha comprendido correctamente que no hay ninguna fuerza infinita, todopoderosa, pues entonces no podria haber drama, génesis, esfuerzo, tragedia, historia ni mito. Sus dioses en lucha se adecuan a la conflictividad del proceso real.

Sin embargo. los dioses del politeismo no son lo divino sin más. o al menos no más que nosotros. Indudablemente hay en la naturaleza fuerzas superiores a nosotros, fuerzas que nos constituyen y que pueden destrozarnos. Habrá sin duda una gran sabiduria acumulada en los milenios que lleva la vida en la Tierra y en sus distintas especies (también en nuestro cuerpo), de la que por cierto nos aleja nuestra civilización, que se apoya fundamentalmente en el distanciamiento técnico, en la idealidad abstrahída propia del lenguaje cientifico, en la medida matemática y no en el sentir. Esos dioses serán más fuertes y tal vez en cierto sentido más sabios (no pensemos que porque podemos matar a un león o a un elefante de un tiro tenemos sin más y sólo por eso más sabiduria; también los bárbaros arrasaron Roma, y los árabes quemaron la biblioteca de Alejandria), pero en todo caso no más originarios que nosotros, no con más dignidad, pues la verdadera dignidad no depende del saber o de la fuerza sino de la autoderminación, de la libertad, y a eso somos llamados nosotros incluso individualmeute. y de una manera más abierta, más consciente, gracias al ilimitado mundo de la reflexión.

La vida, en sus distintas manifestaciones, merece un gran respeto, no sólo porque acumula una sabiduria que pudiera enseñarnos múltiples cosas, sino también un respeto análogo al que podemos tener a nuestros progenitores y a nuestra casa (iqué 
frio y muerto sentiriamos incluso nosotros, y más aún un hombre de tribu, un mundo donde sólo estuviéramos rodeados de máquinas!). Pero nosotros podemos ponerla al servicio de nuestra propia vida y libertad (asi lo comprendió también el hombre primitivo, dirigiendo a ese fin el culto y la magia), y ese seria el limite de toda veneración politeista o de toda conciencia ecológica; no sólo porque asi nos lo enseña la propia vida, sino porque nuestro proyecto humano representa un paso más, un plus, un salto cualitativo respecto a la naturaleza, salto que llamamos razón, donde la libertad llega o puede llegar a su plena conciencia al abrirse a la totalidad de lo real y a su responsabilidad como acto individual. En ese nuevo ámbito, incluso el individuo está llamado a la autonomia, a la configuración de su propio destino.

Por consiguiente, la libertad humana ahonda más en lo divino, profundiza más en lo originario. Comprendiendo esto, el hombre posteriormente elaboró un concepto de Dios como espiritu superior a toda la naturaleza, creador de todas esas fuerzas naturales y de su finalidad, como una inteligencia arquetípica y una voluntad omnipotente, o sea, un Dios a imagen de su ideal de dominio técnico y mágico de las fuerzas naturales. Pero de ese teísmo ya hemos hablado.

Por lo que se refiere al panteismo, éste seria una forma más evolucionada que el politeismo por cuanto que en él hay un mayor trabajo de la razón, de su tendencia a la unidad. Más que como descripción, el término "panteísmo" ha sido usado en cuanto descalificación, e incluso como insulto, porque se ha percibido en êl una tendencia natural o pendiente hacia la cual se inclina con facilidad la razón (¿o habria que decir se desliza y cae?), pues si Dios es la realidad fontal, si toda la realidad procede de Dios, lo que no sea Dios es nada. Pero tambièn a ella se inclina el espiritu poético y el místico desde el sentir. Este panteismo acosmista representa una absorción del mundo en Dios. Ahora bien, en la medida en que a ese Dios, a esa unidad mistica o racional, se la comprenda como Objeto absoluto o como Sujeto infinito, nos remitimos a la critica ya realizada anteriormente.

Otra variante del panteismo seria la posibilidad contraria: no ya "Dios es todo" sino "todo es Dios", es decir, la asimilación de Dios o lo divino con el mundo, por lo que normalmente los teístas 
consideran este panteismo como una forma más de ateísmo: si todo es Dios, Dios no es nada distinto, ningún ente particular, luego no es como tal. En este nuestro caso, el de un panteísmo teleológico, el mundo ya no es tomado como una mera máquina, conforme al determinismo objetivo o científico que antes vimos, sino como una unidad orgánica (con "alma"), siendo lo divino la fuerza configuradora, la imaginación productora de naturaleza organizada, de la naturaleza en general y de los mismos dioses del politeísmo: la natura naturans.

Y ella es ciertamente una manifestación de lo originario, pero como hemos ido viendo no es la única. Además, el panteísmo. fijándose sobre todo en la unidad (y teniendo en cuenta que solemos comprender reflexivamente todo según el modo de ser de las cosas, a las que primariamente estamos volcados), no suele pensar a fondo la diferencia y la multiplicidad: por ejemplo la diferencia entre el mundo concreto y lo divino (como ámbito también de posibilidad), o entre la natura naturans y el individuo humano libre, o sea, el salto que se da en el ser racional, de modo que no resulta aceptable un determinismo teleológico en contra de la experiencia ética y anulando lo originario de la libertad individual. Tampoco suele pensar a fondo la realidad de la multiplicidad, que no es meramente ilusoria, como no es ilusoria la responsabilidad del individuo libre como tal individuo, que le enfrenta a una distancia y una soledad irrenunciable: o la multiplicidad incluso de sentidos, de creación imaginativa, no siempre compatibles, una multiplicidad también trágica, en lucha y muerte. Otra cosa seria un panteismo donde el todo construye a los individuos, pero a la vez los individuos van const ruyendo de forma originaria al todo, con lo cual éste siempre quedara abierto (no como si fuera una unidad objetiva) y los individuos no fuesen meros actores, sino también autores.

El panteismo no sólo no puede pretender que su dios sea una unidad objetiva, sino tampoco subjetiva, una inteligencia proyectante. pues le faltaria una relación personal con un otro igual y careceria de cuerpo orgánico pues el universo como un todo no tiene la reflexividad propia de la vida y además la vida (como la finalidad y la subjetividad en general) sólo puede concebirse como un proyecto particular dentro de la no vida o materia, o sea, dentro de un mecanismo que es lo que la convierte proplamente en natura- 
leza. Hay que reconocer, sin embargo, que en el panteismo caben múltiples variantes, y que aqui los distintos matices son esenciales. Pero mejor que detenemos en ellos será pasar a la parte propositiva desde donde se podrán ver sus diferencias con los diversos panteísmos históricos.

\section{4.- El modo de ser de lo divino}

\section{A. - "Teologia positiva"}

En nuestro recorrido anterior hemos encontrado elementos originarios que configuran la realidad, al menos la realidad de la que podemos hablar con fundamento: la materia o energia, la conciencia-autoconciencia, la libertad y la imaginación productiva (tanto de conciencia organizada como de naturaleza orgánica). A través de ellos pasemos a analizar cómo se nos muestra lo divino.

\section{a.- Como materia o energía}

Ella fue descubierta en cuanto irreductible a mi acción, tanto a mi acción ideal de conocer como a mi acción real teleológica. Es lo que la subjetividad no puede crear (sólo transformar y darle diversos sentidos) y ha de ser necesariamente dado, contrapuesto, señalando mi pasividad (o sensibilidad), haciendo presente la otra realidad que yo no protagonizo y, en contraposición. objetivando mi realidad.

Al ser lo dado, lo irreductible a mi acción, eso divino se manifiesta como don (y posibilidad de dones), pura gratuidad sin otro fundamento (es porque es), que sirve a su vez de fundamento (Grund), sustento (hypokéimenon), suelo a toda otra manifestación al ser el terreno de lo real. También los otros tres aspectos de lo originario, justo por su carácter de originario, son un don, de modo que podemos decir que estamos arrojados a la libertad, o que el pensamiento nos es dado; pero ninguno nos lo hace tan manifiesto como la materia-energía al ser lo dado a la acción con la que primariamente me identifico, lo pre-su-puesto por ella. 
Aqui lo divino se nos manifiesta como realidad, presencia y actualidad, pero una presencia y un estar en contraposición dinámica donde se marcan limites, finitud, división. Es el terreno donde se establece lo mio y lo del otro, mi cuerpo y el suyo, de manera que la realidad mía no es la de lo otro, y a la inversa: la energia que yo soy no la tiene el otro. si me como la del otro (por ejemplo la de una fruta o la de un corderol y la hago mia lo mato. y lo que yo bebo no puede bebérselo otro, etc. Con ello lo real se extiende como partes extra partes, se constituye en espacialidad real y presencia que, al ser don, es también la posibilidad de lo contrario, de ausencia de don y ser con ello arrojado fuera del ser ("a las tinieblas exteriores").

Por tanto aqui lo divino u originario se manifiesta como el terreno del poder. Ser es (en este aspecto) poder, en cuanto que sin la presencia, sin la energia, no hay ser; poder que, al configurarse como partes extra partes, como exterioridad, aparece también como tener: sin tener no hay ser. Ahi cada uno habrá de afirmarse. buscar su espacio. Lo divino, como terreno de la afirmación, de la posesión en la finitud, es también conflicto y lucha, no sólo armonia (Marte es uno de los dioses). El egoísta, el avaro, el tírano, el capitalista o el politico sin escrúpulos, el que juega sucio, el ganster, etc. aquéllos para los que su dios es la lógica del poder y del dinero, no se equivocan al concebirlo como lo divino, sino al pensar que eso es lo único divino, la única manifestación de lo originario que tuviéramos que vivir y elaborar. Justo su carácter de pre-su-puesto es lo que hace posible y fácil tal error (ningún error se funda en la nada absoluta).

Asimismo, al ser también presencia y don, es posibilidad de estar juntos y encontrarse, dar y compartir, pero eso limitadamente. pues estamos en el terreno donde se establece la limitación y la finitud. Toda solidaridad tendrá que contar con límites, y lo contrario sería pensar ilusoriamente que la materia-energia podemos crearla y disponer de ella según se nos antoje. Pero eso no quiere decir que no debamos trabajar a fin de agrandar nuestras

disponibilidades, sino todo lo contrario. A esa tarea se dedica por ejemplo el desarrollo científico y técnico, aunque no carezca hoy en 
dia de graves defectos economicistas y ecológicos, al no tener en cuenta otros aspectos de lo divino.

Veiamos que es don y presencia, pero también conflicto y exclusión, exterioridad y espesor, lo que se niega al otro y se le oculta, lo que se nos oculta a nosotros mismos como resistente a nuestra propia acción. Por esa contraposición suya a lo subjetivo se nos manifiesta tambiên como opacidad, lo macizo y cerrado, haciendo imposible el ideal de una total autotransparencia conceptual hegeliana, o la reducción de lo originario a la espontaneidad libre, como pretende la ontologia de la libertad. Ninguna de las manifestaciones de lo divino deriva de la otra, se reduce a otra, justamente porque son originarias y como tales se nos manifiestan en su contraposición, aunque todas ellas estén entrelazadas sintéticamente entre si por esa misma contraposición. Incluso la comprensión de la originariedad de la materia o energia, que pareceria lo primero y más independiente, se obtiene, según vimos, por su contraposición con lo meramente subjetivo, en cuanto pre-su-puesto. Dado que conocer es distinguir, no podemos llegar a un elemento que no sea por contraposición. Los cuatro aspectos de lo originario no se pueden reducir los unos a los otros, por ejemplo diciendo que la materia-energia sale de la conciencia, o a la inversa, o que conciencia es lo mismo que energia dado que siempre va unida a ella, porque no lo está de modo analítico, sino sintético, ni podemos afirmar con fundamento que toda energía conlleve conciencia. Ni tampoco podemos hipostasiarlos en un ser transcendente sin cosificarlos ni decir más de lo que podemos con fundamento (suponiendo un Objeto o Sujeto transcendente que ya ha sido criticado en puntos anteriores de este artículo), sino sólo describirlos tal y como se nos presentan al final del camino, se entiende del camino o método transcendental tal y como aqui ha sido llevado a cabo. Por eso es insostenible todo monismo teórico (de nuevo una pretensión de anular toda finitud), y aqui en concreto todo monismo materialista. 
b.- Como conciencia-autoconciencia o pensamiento

Es idealidad, apertura reflexiva a la realidad, saber de sí y de lo otro, luz o espacio ideal de manifestación.

En cuanto idealidad y apertura es flimitación y distanciamiento, introducción de la nada, de una nada que no es la nada del ser (como pretende Sartre), pues entonces seria nada sin más, sino la nada del ente, o sea, que es otro modo de ser no presencial. Es el modo de ser más contrapuesto a la materia-energia. como se contraponen la acción ideal y la acción real, la mera forma y la materia-forma, posibilidad y realidad, concepto y objeto, etc.; aunque eso no quiere decir que pueda ser sin ella, que estén separados cósicamente como partes extra partes, sino que están unidos sintéticamente, porque el pensamiento no tiene el modo de ser de la cosa o la materia-energia, sino el de una acción ideal que hace posible que se manifiesten las cosas y la materia-energia. Si es verdad que todo acto de pensamiento es también energía, no se trata aqui de una identidad analitica, sino sintética; sin energía no habria nada, y el pensamiento canaliza esa energia mediante la libertad y la imaginación, como después veremos.

Gracias a esa contraposición y distancia que el pensamiento establece entre si y la materia-energía, la realidad se hace presencia en cuanto que la idealidad del pensamiento, contraponiéndose, se la hace presente y ella se comprende a sí misma como idealidad y apertura de posibilidades ideales. Es ilimitación, luego apertura de ilimitadas posibilidades ideales, lo que alcanza su máxima manifestación en lo que se denomina razón o petición ideal de lo absoluto. Es distanciamiento, luego lo divino no es un ente compacto, lleno, macizo, simple materia-energia-presencia, sino también posibilidad de ausencias, de soledad, desde donde nacen posibilidades de verdadera novedad, de creación, y también de vacío y nostalgia. Buscamos la unidad con lo divino, o con una realidad plena, como si pudieran ser compactos, pero eso mismo divino que somos en cuanto pensamiento, en cuanto conciencia-autoconciencia, nos introduce siempre en la distinción, en la diferencia. La mayor unidad posible conlleva ella misma la distancia insalvable de lo originario mismo con respecto a sí. La descosificación de lo divino implica que nuestra plenitud no puede ser cósica (cielo). Buscamos una unidad anterior a toda distinción, una unidad cósica que seria en realidad la muerte. y "sólo" podemos alcanzar una unidad 
superior y más rica, más compleja y más dificil, más frágil y costosa, que integra siempre la originaria diferencia y con ello nuestra constitutiva finitud, sin la cual dejariamos de ser.

Asimismo, la orlginariedad (o transcendentalidad) del pensamiento hace posible la búsqueda de la verdad y el diálogo (no ya pura lucha y dialéctica) gracias a ese distanciamiento respecto de la energia-presencia. Lo originario que se nos manifiesta en la subjetividad no es sólo ese distanciamiento ideal de la conciencia transcendental, de modo que pudiéramos encontrar la subjetividad pura haciendo "epojé" de todo lo demás; un sujeto meramente ideal (si eso pudiera darse) dejaria por ello mismo de comprender la realidad y a si mismo, pues no podria contraponerse realmente a la otra realidad. Pero negarlo como momento de la subjetividad (y de lo originario en general) seria vaciar de contenido toda afirmación, toda pretensión de verdad y de diálogo, y, en definitiva, todo conocimiento. Incluso aquella afirmación que dice que toda verdad es histórica o una mentira útil se presenta como verdad universal y no mentirosa, o en caso contrario entrariamos en un decir paradójico que a la postre no diría nada porque lo que dice lo desdice y se niega a si mismo. Si todo fuera mentira, o máscara, o sueño, no habría modo de contrastarlo, de enterarse y liberarse y. por tanto, seria además una afirmación perfectamente inútil. Dado que comprender es articular y distinguir, descubrir la mentira sólo es posible dentro de una experiencia y un decir que se afirma como verdadero. Y a la inversa, sólo en contraposición con lo que se oculta o engaña tomamos conciencia reflexiva de la verdad. De ahi que a la verdad le sea esencial también el ocultamiento (Heidegger): con lo cual vemos de nuevo la imposibilidad de una total transparencia, de una luz plena, de reducir lo originario a la actividad ideal, a un pensamiento que se piensa a si mismo (Aristóteles).

No se puede absolutizar el pensamiento poniéndolo como lo único originario, o como si nuestro destino fuera el de ser simples espectadores neutros y apáticos de la realidad, meramente teóricos. Pero tampoco se le puede negar su carácter de originario diciendo, por ejemplo, que eso lo es el lenguaje. El lenguaje humano delimita ciertamente la conciencia reflexiva, pero no toda conciencia, a no ser que llamemos lenguaje a la forma de todo acto de conciencia. El lenguaje es tal y es significativo porque está comprendido por una conciencia que no lo dice todo, que sabe más de lo que dice y de lo 
que se puede decir (la riqueza de la experiencia sensible e imaginativa es inefable, por no hablar de la amorosa, de la estética o de la mistica), por una conciencia que lo utiliza, lo crea y lo transforma. Es verdad que no es un útil que quedara tan exterior a mi como un boligrafo, sino que configura mi conciencia empirica más profundamente que la técnica (la subjetividad es transformada por aquello mismo que crea, pues no es una substancia transcendente). Pero eso sólo es posible en cuanto que es comprendido por la idealidad de la autoconciencia transcendental subjetiva.

De igual modo, cuando se dice que "la autoconciencia en el sentido más propio es en realidad la imagen de nosotros mismos que los otros nos transmiten", un "fantasma social", y esto se dice "en el sentido de un desenmascaramiento de su pretensión de inmediatez y ultimidad" (G. Vattimo, Etica de la interpretación. Paidós, pp. 124-5, refiriédose a Nietzsche), se está confundiendo la conciencia empirica (no originaria) con la transcendental. La conciencia empirica depende del mundo en orden a su determinación objetiva como cualquier otro fenómeno (Kant. Crítica de la razón pura A 226, B 274ss). La transcendental es condicion de posibilidad de la empírica y del fenómeno en general, condición ideal y originaria, aqui en concreto de que podamos enterarnos qué piensan los demás de mi, que podamos darnos cuenta de que nuestra conciencia empirica depende de la opinión de los demás (si no traspasáramos idealmente los limites y las determinaciones no los podriamos conocer como tales; estarian puestos, pero no para nosotros), y que podamos proyectar idealmente la posibilidad de liberarnos progresivamente de esa atadura en caso de ser opresiva. Esa conciencia transcendental no me puede ser dada por los demás (¿y quién se la habria dado a ellos?), pues entonces no seria yo el que se enterara, no sería mi comprensión; me puede ser dada una cosa, pero la comprensión no tiene el modo de ser de la cosa (Heidegger). Ni la inmediatez de la conciencia transcendental es la de la cosa consigo misma (sería opacidad), sino la de la esencial apertura a si misma y a la realidad, distinguiéndose de ella pero estando esta realidad siempre presente. Conciencia de algo (conciencia empirica) y autoconciencia transcendental se coimplican, pues sólo sé algo si sé que sé, y a su vez esto último únicamente puede darse en la acción de conocer, ya que conocer como tal es pura acción ideal (transcendental) y no substancta independiente 
de la misma: aunque después pueda venir un acto de reflexión distinguiendo los diversos aspectos de un mismo acto.

Por otra parte, que esa idealidad transcendental se ponga al servicio de diversos intereses no quiere decir que sea engendrado por ellos, que se pueda deducir metafísica o psicológicamente de ellos, ni que sea idéntica a ellos, pues entonces no habria distanciamiento y los intereses no podrian conocerse a si mismos, ni sabrian (ni sabriamos) que son intereses. El originario distanciamiento que la conciencia introduce en lo originario mismo, destruye toda identidad cósica o analitica (monismo ontológico) con la que queramos pensar la realidad radical. Lo originario es también pluralidad y diferencia, como corresponde a la libertad y a la finitud. La unidad primaria a la que tiende la razón, sobre todo cuando filosofa, no ha de ser interpretada como una unidad ya dada, cósica, analítica o teórica, el Uno lya sea materia, energía, conciencia, espiritu, alma, libertad, etc.) a partir del cual seria imposible deducir la finitud, la multiplicidad, la diferencia, sino que ha de ser vista, por la primacia de lo práctico, como una unidad sintética, una tarea de sintesis, donde los elementos se integran sin confudirse, sino manteniendo su diferencia y autonomia originaria $y$, por tanto, inevitablemente y en alguna medida, el conflicto.

\section{c.- Como libertad}

1.- Es espontaneidad. Podriamos decir que es energia protagonizada gracias a la reflexibilidad de la conciencia-autoconciencia. y a la inversa, la conciencia es la idealidad del distanciamiento que la libertad tiene respecto a todo lo dado y de ésta obtiene su sentido, interés, dirección. El saber se enraiza en la realidad de la libertad, pero ambos son originarios, sólo que están enlazados sintéticamente entre sí como dos momentos de una misma subjetividad.

En efecto, la libertad es una acción real que, al ser subjetiva, al protagonizarse a sí misma, es también ideal, sabe de sí, y cuya máxima conciencia de si aparece como razón práctica, como imperativo moral. Pero en cuanto conciencia no sólo sé de mí sino también de la realidad que yo no protagonizo, del mundo y de los otros, y sólo en esa contraposición las distingo y soy consciente de 
ambas realidades. Luego la idealidad de la conciencia (como corresponde a la idealidad) es de suyo llimitada, se abre a la totalidad de lo real, y por eso el sujeto conoce sus limites reales y a la otra realidad. Por tanto, la idealidad de mi conciencia no sólo se contrapone a la realidad que yo no protagonizo, sino también a mi propia realidad a fin de distinguir entre lo limitado de ésta y la ilimitada idealidad de aquélla. Aunque la libertad sea una acción real-ideal, en el propio sujeto se distingue esa libertad de la mera idealidad de la conciencia como condición de posibilidad del reconocimiento de ambas; de ese modo no me pongo como realmente ilimitado al ser idealmente ilimitado, ni confundo mis pensamientos y fantasías con mis acciones práctico-pragmáticas. En conclusión, representan dos momentos originarios diferentes. El momento originario del pensamiento se llama "autoconciencia": en ella, la conciencia se contrapone a la realidad en general como mera idealidad, si bien como una idealidad que sólo puede ser gracias a la realidad, en contraposición a ella y para saber de ella.

La libertad es espontaneidad protagonizada, luego responsable de sí, que se pone a si misma en devenir para llevar a cabo su tarea de realización: si estuviera ya realizada en la energia-presencia no sería acción ni subjetividad sino mero objeto. Luego es querer originario, que aparecerá en el ámbito de la conciencia como deseo y voluntad. Es querer y, por consiguiente, ámbito de posibilidades que pujan por el terreno de la materia o energia en forma de deseo. Querer que se toma a sí mismo como tarea originaria, luego ámbito de posibilidades reales que se presentan como deber ser o imperativos morales (voluntad), no ya sólo en la forma de posibilidades ideales y meramente hipotéticas, como ocurria en el pensamiento.

Por tanto, también según este momento, lo originario no se manifiesta como algo ya enteramente dado o hecho, estando ahi de manera objetivamente absoluta, perfecta, acabada, como presencia o actualidad eterna, sino que comporta también ausencia y querer. lo cual abre la temporalidad hacia el futuro de manera real, práctico-pragmática, y no ya meramente ideal como en el pensamiento. Sin ello no habría proceso ni mundo, ni subjetividad, ni evolución, ni historia, pues la acción espontánea de un Absoluto dado, al serlo ya todo, sólo podria ir de sí a si sin salir de sí, y seria por tanto reposo, no acción. A partir de él no hay dedución posible de la finitud, o sea, del mundo y de la subjetividad, como tampoco 
es posible pasar de la realidad finita a un infinito real en un proceso de acercamiento que nunca podria concluir; luego no hay tránsito posible de lo uno a lo otro. Por tanto, afirmar la existencia de ese Absoluto va contra los datos que poseemos, haciéndolos imposibles, misteriosos (el misterio de la creación), y dado que éstos son, ese Absoluto o infinito real no puede ser.

Si pensamos lo divino como un Absoluto objetivo, como algo que sencillamente está más allá del mundo y del sujeto, sin mundo, sin negación ni límite, etc. lo hemos cosificado, estableciéndolo como algo cerrado, y hemos vaciado ontológicamente el mundo y la libertad. Ambas cosas pierden sentido. Ya hablar de Absoluto y de Infinito conduce a pensarlo como algo dado y cósico (vorhanden) aunque no esté en este mundo. Todos los matices que queramos después añadir para corregir en lo posible gruesos sinsentidos, no evitarán el malentendido de fondo que nos conducirá, en el límite. a la afirmación del contrasentido y del misterio, conceptos con los que muchas veces se quiere dejar simplemente de pensar y cubrir el error sin desvelarlo.

2.- La libertad es abismo. Ella abre un ámbito real de posibilidades que, al formar un mismo acto sintético con la ilimitada idealidad de la conciencia, tiende a ser un ámbito ilimitado de posibilidades. Esto representa un abismo donde el querer puede perderse si no logra encontrar y reconocer las posibilidades más reales y propias para llevarlas a la presencia de la energia, pues lo real no es ilimitado ni todas las posibilidades son apropiables por cada uno (o incluso por el hombre en general), sino aquéllas que entroncan con el pasado, con las acciones pasadas de la imaginación productiva (como después veremos), y están posibilitadas por él y por la fuerza-energia que poseemos, las que están indicadas por el deber ser, y las que abran a su vez un mayor abanico de posibilidades y de futuro, es decir, las más habitables por seres libres dentro de los limites de la finitud. Hay posibilidades que parecen idealmente más gozosas o brillantes. incluso más creativas y heroicas, pero que al no ser las más reales y propias, sólo hacen seducir y conducir al fracaso y a la destrucción de la misma subjetividad ("y seréis como dioses").

Ese abismo (real y más aún ideal) es el fondo sin fondo de lo divino, lo selvático u oceánico. como el magma del núcleo terrestre. 
como la falta de pilares del universo (la Tierra no está apoyada en un elefante y éste en un sin fin de tortugas, sino que es una nave en el espacio con el tiempo limitado), lo que puede deshacer como terremoto cualquier fundamento cósico que pretendamos poner como absoluto, lo en principio caótico, lo explorable en cierta medida por los héroes y fundadores de cultura al ser la fuente de la creatividad, $y$ todos de alguna manera estamos llamados a ser héroes, es decir, a ser libres, a meternos en ese pozo fontal para sacar el agua originaria de la vida. su sentido, renovando el acto fundacional de la comprensión del mundo. Este apecto de lo divino produce pavor, porque el abismo y el caos nos destruiria como seres organizados, reglados, ritmicos, y en ellos no sabemos a qué atenernos (no hay formas regladas y reconocidas), o cómo salir (no hay caminos trazados). En este sentido, lo divino aparece como "fuego consumidor" (Deuteronomio IV, 24), cuya visión directa supone para el hombre peligro de muerte (Exodo XXXIII, 18-35). Pero hay que reconocer que lo más corriente es que el hombre no se encuentre tan (pre)ocupado o angustiado por este aspecto de lo divino, sino más bien por su lucha en la obtención de la energía, por su espacio en la presencia, por "las cuestiones materiales"; este aspecto (también originario, no lo olvidemos) domina en no pocas manifestaciones religiosas, ritos y plegarias, hasta tal punto que muchas veces ha conducido al miedo y rechazo de la libertad, a la instalación de diversos modos de esclavitud. Pero entonces la realidad se angosta, el hombre se asfixia.

La libertad, al ser algo originario, es un riesgo necesario. Su riesgo, como hemos visto, reside en su grandeza insondable, inagotable a nuestras capacidades, en el peligro, "diabólico", que representa el carácter seductor de algunas posibilidades pretendidamente grandiosas pero ajenas a uno mismo, por la posibilidad de locura, etc. Lo divino es también terror y noche, frente a lo cual el hombre siempre ha buscado protección y auxilio en ritos, objetos, fórmulas, etc (por ejemplo, el "Libro de los muertos" egipcio). Salir de ese laberinto propio requiere no sólo arrojo, imaginación y conocer algunas de las pautas que las distintas civilizaciones han ido elaborando en forma de ritos de iniciación o de psicoanálisis o de regresiones, etc, sino también el hilo de Ariadna: el amor. O como dice el don Juan de Castaneda, es preciso encontrar entre todas esas posibilidades "nuestro camino con corazón". Es decir, se 
precisa un punto de unión con el gozo de la presencia (lo que podemos ver en los niños cuando juegan sin que se dejen amargar por las limitaciones de lo real), un puente que el mismo querer tienda entre lo real y lo posible, ligándolos, afirmándolos y fecundándolos. Ni un aplanamiento total y servil ante lo cotidano, ni un furor fanático contra lo real y sus limitaciones en pro de posibilidades fantásticamente grandiosas, de cielos y superhombres.

3.- La libertad es petición de orden. Frente a ese abismo, que moralmente se nos presenta como posibilidad de bien y de mal, es decir, que la libertad puede construirse o destruirse a sí misma, ante esa posibilidad de destrucción, la libertad es ella misma petición de saber y de pautas para actuar, y no sólo de pautas técnicas sobre cómo habérselas con la energia-presencia. sino también y sobre todo de pautas para habérselas consigo misma. de pautas iniciáticas y de pautas morales. Es aqui donde se asienta principalmente el fenómeno religioso, como después veremos.

Lo originario es también petición de orden (cuya máxima expresión se denomina razón práctica), pues sin él no se construiria en la presencia, ya que no llegaria del abismo a ella al no haber un querer que impulsara salir del abismo y del caos, y no mantendria un ritmo (orden) en el conflicto de la presencia y se volveria al caos y al abismo. Esa es la fuerza y sacralidad que tiene lo desbrozado, la tradición. Salirse del orden es encontrarse con la tra divina. hasta Zeus está sujeto a ciertas necesidades. Esto se nos flexibilizará cuando hablemos de la imaginación productiva, pero el orden moral no es sin más una ley que nos venga de fuera, la ley del padre; si el padre se fuera y los niños quisieran vivir sin orden alguno en la casa, las carencias e injusticias que pronto se establecerian les harian ver que el orden moral era también una exigencia propia y originaria.

La libertad es petición de orden porque se sabe caos e indeterminación, y a la inversa, se sabe indeterminación, posibilidad de bien y de mal, de construcción y destrucción propias, porque se invita moralmente a si misma a elaborarse como tal libertad. En esa invitación moral ella toma conciencia plena de si. Ambos aspectos son originarios y el uno no puede darse sin el otro. Sin embargo, por nuestra herencia cultural tardorromántica, solemos identificar libertad con ausencia de toda norma, es decir, con un solo aspecto 
de la misma, dado que anteriormente se hizo excesivo hincapié en el otro aspecto (jerarquía, obediencia, orden tiránico), sin darnos cuenta que también procede de la libertad nuestra exigencia de respecto y de un orden justo. Se ha ensayado en algunos paises una planificación politico-económica total dando lugar, entre otras cosas, a la asfixia de la propia libertad, como también conduciria a su destrucción el puro laisser faire; se precisa una sintesis de ambas direcciones, sintesis dinámica e históricamente variable, como sucede asimismo en nuestras propias vidas.

Desde este punto de vista moral lo divino se nos presenta o es:

a).- En primer lugar, el ideal de un orden moral del mundo, de libertad y de justicia, que hemos de llevar a cabo con nuestra revolución interior moral y con nuestro esfuerzo, pero sabiendo que. como todo ideal, representa un proceso hacia el infinito, inacabable, inalcanzable (Fichte). Nunca podremos construir un cielo en la tierra (aunque nuestro deber sea acercarnos a él lo más posible), como creyeron algunos utópicos revolucionarios. Y no sólo porque nuestro deseo, ilimitado, nunca será colmado (iqué ingenuidad antropológica eso de "a cada uno según sus necesidades" (Marx)!), sino también porque la libertad es indeterminación y, por tanto, posibilidad siempre de mal, de autodestrucción. Una voluntad que sólo pudiera ser santa no seria libre, de modo que la transgresión estará siempre presente en el mundo. Frente ella nos damos cuenta de nuestra tarea moral, sin querer con ello decir que no llamemos "transgresión" a la transgresión, pues entonces no cumpliria su papel de contraste.

La subjetividad está siempre en proceso, devenir, esfuerzo, proyecto, trabajo. Sólo entonces es. Ese es el mundo de los hombres: ni el conseguir lo absoluto, ni el tirar la toalla porque no se consigue. Nuestro destino no es la plenitud, ni la plenitud del deseo en un Objeto absoluto o en "Un mundo feliz" de A. Huxley, ni la plenitud moral en un mundo perfecto y santo gracias a un Sujeto infinito, pues ambos, anulando la finitud, acabarian con la misma libertad y la subjetividad en general. La subjetividad está necesariamente instalada en la dualidad, en la distinción, en el conocerse a sí misma en cuanto que soprepasa idealmente lo dado y se distingue, en la individualización, y por tanto en la finitud y en la muerte. Si la libertad pudiera ser saturada con algo, si se realizara 
plenamente en sentido objetivo, dejaria de ser libertad para convertirse en su objeto identificándose con él; dejaria de tener conciencia de sí como subjetividad, como libertad no atada, pues toda la idealidad se habria objetivado y no habria distinción. A la subjetividad le es constitutiva la finitud, y por eso sólo podremos alcanzar cierta plenitud simbólica, en la que se vive y se comprende la unidad, pero a la vez se mantiene como real (y no como mera ilusión) la diferencia. Nuestro destino no es detener la luz, sino dejarla que caliente nuestro corazón y que después se marche, que pase a otro. En la plenitud simbólica nos invade un sentimiento de ternura (los heideggerianos lo llaman pietas).

b).- Pero lo divino no es sólo el hacia dónde, sino más propiamente el de dónde, la originariedad transcendental. la luz y la fuerza o vida que hacen posible ese proyecto, la fuerza desplegada en el proyecto de liberación, el compromiso efectivo por la justicia, ese pensar y esa libertad que lo hacen posible en el individuo y en la comunidad, que soy y a la vez me rebasa, que somos y que parece también incluir a la propia naturaleza. En esto también se halla implicada la imaginación productiva.

\section{d.- Como imaginación productiva.}

Ya sea que se manifieste como natura naturans, o como configuración del mundo objetivo, del mundo práctico o del mundo estético. la imaginación productiva es una acción originaria que consiste en ser puente entre el abismo (ideal y real) y la presencia. entre la posibilidad y la objetividad, entre la libertad y la finitud. Ella es configuración y sintesis, organización de la energia en figuras comprensibles, en presencias orgánicas y vivas, en subjetividades finitas y reales. Es la que delinea limites con sentido y habitables, la que marca el ritmo, la vida y la muerte, la que inicia el juego, la que establece pautas y abre senderos, la que construye formas vivas, civilizaciones y lenguajes, la que ensaya y poetiza el mundo, en lo cual nosotros somos escenario, actores y coautores. Ella es el punto de unión entre lo propiamente subjetivo (libertad y conciencia) y lo propiamente objetivo (materia-energia), unión que es un acto originario de sintesis que no se deduce analiticamente 
de ios demás, sino que es tan originario como ellos, pues sin él los otros tampoco podrian ser transcendentalmente afirmados (sólo de forma transcendente y cosificada), dado que sólo se manifiestan como elementos contrapuestos en esa sintesis.

Tampoco aquí lo divino es algo omnipotente, y no sólo porque la imaginación productiva también se equivoque, inicie callejones sin salidas o nos presente escenas de dolor absurdas e irrecuperables en el mundo, sino sobre todo porque no crea ex nihilo la energia-presencia, sino que ésta le viene dada y sólo la configura y transforma, y además porque progresa, según vimos, apoyándose en sus anteriores productos, o sea, en su pasado, constituyendo de este modo un pasado real y no meramente ideal como en el pensamiento. Al tener que apoyarse en las configuraciones anteriores, éstas posibilitan unas acciones e imposibilitan otras. Por ejemplo, nosotros no podriamos prescidir del oxígeno, pues todo nuestro pasado biológico ha sido construido contando con él; lo mismo ocurre con la historia colectiva o personal. Ese pasado deja abiertas por tanto posibilidades y marca imposibilidades; esto de modo más o menos abierto, pero que hacen más realizables y propias unas posibilidades que otras, según vimos al hablar de la libertad.

Se crea asi un cierto orden y significatividad al borde del abismo y de la lucha por la energia-presencia para que sea casa y morada. porque el abismo y el caos nos destruiria como seres organizados. Es un acto fundacional: del ritmo, de la vida, de la forma humana. Este acto fundacional de nuestra subjetividad humana (como individuo y comunidad necesariamente a la vez) y los elementos que lo integran son el contenido básico de la experiencia religiosa, o sea. que se viven y se comprenden como lo sagrado. Eso es lo que narra el mito y demás textos religiosos en cuanto palabras y acciones prototipicas de dioses y héroes, de profetas y pontífices, dado que se enraiza en un pasado primigenio que nos sostiene y nos da la norma. Ellos representan el puente (sintesis) entre la energia-presencia y la libertad-conciencia. Los héroes o genios lo son porque en el caos, tanto el de la libertad como el de la energia, han sido capaces de construir y reconocer figuras habitables, debrozar caminos. No sólo proporcionan cultura y pautas para habérnoslas con nuestra libertad, sino que también han conquistado el suelo y 
las técnicas necesarias para sobrevivir en la lucha por la energia-presencia.

Además, ese acto fundacional se comprende como lo sagrado porque significa un salto portentoso: por muy pequeño que aparezca en el exterior, marca una dirección completamente nueva, abriendo un abanico de posibilidades antes insospechadas. $Y$ porque cada cultura, cada religión, cada mitologia, es una nueva concreción o interpretación de lo divino; la regla de la imaginación productiva en la sintesis es ya una interpretación, un modo de ordenación y comprensión, una articulación de la experiencia, y sin eso no habria conciencia ni sentimiento. Se trata de una nueva sintesis de espontaneidad y de finitud, la cual va acompañada con un nuevo sentir originario, pues el sentir es la conciencia primaria. De ahi la intensa emoción y admiración, atracción, temor y angustia, propias de lo religioso, de lo mítico, y de su retorno místico, pues en el acto fundacional es donde se sienten en su mayor intensidad los distintos momentos de lo divino debido a la cercania de la imaginación productiva con su objeto. Ese acto fundacional de lo humano da lugar al "molde del hombre" como lo llama Don Juan y que, según él, es lo que los misticos contemplan, interpretándolo de manera errónea como un Dios omnipotente y omnisciente (C. Castaneda, El fuego interno, Swan, pp. 288ss).

Todo eso, y el riesgo de lo nuevo, de estar al borde del abismo de la libertad y luchando por el dominio de la presencia-energia. hacen que esas formas de vida, que surgieron como la concreción de una posibilidad entre otras, se consoliden, se hagan rito, se tomen como las ünicas posibles, se petrifiquen, se piensen eternas, la única ortodoxia. Sus pautas son defendidas como se defiende la propia identidad, pues son las que han configurado a la comunidad y al individuo, el sentido de su existencia. Se toman entonces como conceptos univocos lo que son simbolos de carácter analógicos y abiertos a la pluralidad de significados: por ejemplo, se comprende el "es" de "el infierno es" en el mismo modo de ser de "la Luna es". Por tanto, la subjetividad habrá de estar superando siempre el miedo y la pereza para afirmar su autonomia y no cosificarse, para recuperar, desde su libertad y su imaginación, la espontaneidad propia de ese acto. Encontrará ciertamente que habrá pautas básicas para esa forma de vida como consecuencias de las primeras decisiones, pero, al beber de la misma fuente de creatividad, las 
renovará, las recreará como posibilidad, abriendo nuevas posibilidades, perspectivas, otras formas de comprensión y acción, retomándose como libertad y no siendo mera estatua o eco, pues la libertad sólo llega a su plena realización en el ámbito de la pluralidad y de la posibilidad, del juego y del ensayo.

La configuración y orden establecidos en el acto fundacional es la precomprensión básica de la que partimos. Pero hacer de este aspecto lo único divino sería convertirse en estatuas, en repetidores mecánicos. Tampoco se trata de recharzarlo, de apartarse compulsivamente de él, pues lo más probable es que nos perderiamos en el abismo originario, anulariamos la posibilidad de comunicarnos con los otros, careceriamos de pautas para salir del laberinto, nos encontrariamos con "la ira divina", con un "dios celoso" por su ley, es decir, con el caos y sin ayudas para saber a qué atenernos, por tanto con la angustia, el horror, y la muerte. Pocos héroes sobreviven a ello y son capaces de irse al desierto como Moisés, encontrarse con lo divino y fundar un pueblo, una cultura. Aunque posiblemente sin tanta fuerza, nosotros somos también y originariamente esa imaginación transcendental, puente entre el abismo y el orden, de modo que para realizarnos como tal, hemos de comprendernos también como posibilidad renovando ese acto fundacional de configuración, dialogando con él, viviéndolo como decisión y fuente de posibilidades, confiriéndole nuevas formas habitables, ya sean poéticas, cientificas, técnicas, de estilo de vida, etc.

\section{B.- "Teologia negativa"}

Partía esta investigación de la afirmación aristotélica de que el ser se dice de varias maneras. No podemos comprender el "es" del mismo modo cuando decimos "el agua es o existe", que si afirmamos "el hombre libre existe" o "lo divino es". En los tres primeros apartados hemos ido viendo que lo originario no puede ser afirmado ni en el modo de ser de los objetos, ni en el de los sujetos.

Ya hablar del modo de ser de la libertad humana nos resulta dificil dado que nuestra conciencia reflexiva está habitualmente volcada y ocupada con los objetos del mundo, de modo que el lenguaje se halla fundamentalmente referido al modo de ser del objeto. La conciencia reflexiva alcanza a comprender el modo de ser de la libertad cuando da un salto con respecto a la reflexión propia 
de la vida cotidiana e incluso respecto a la reflexión de la ciencia, y retorna a los origenes constitutivos de la subjetividad mediante una reflexión transcendental. De este modo se pone limites al ámbito de la reflexión teórica y se descubre la acción originaria, tanto de lo teórico como de lo práctico y pragmático. donde el sujeto se pone y se sabe espontáneo y libre, se atribuye a sí mismo sus pensamientos y acciones, $y$ se invita moralmente a realizar su propia libertad. Porque lo sabemos ya prerreflexivamente, actuamos y nos proponemos fines, nos atribuimos nuestros pensamientos y nos distinguimos de la realidad que no protagonizamos.

Algo parecido ocurre con lo originario, tan alejado de la abstraída idealidad de los conceptos, intrumentos de la conciencia reflexiva. Retomarlo reflexivamente, desde la reflexión propia de la filosofia, requiere un gran esfuerzo de retorno y un enorme cuidado para desbrozarlo de formas de pensar propias a otros modos de ser. Pero es posible, porque al igual que ocurre con la libertad, hay una experiencia prerreflexiva de ello. Esa es la que el mito y demás relatos religiosos intentan interpretar y fijar en la conciencia. Lo hacen por medio del simbolo, creación de la imaginación productiva y cercano al sentimiento, polivalente $\mathrm{e}$ inagotable al concepto univoco, si bien la conciencia mítica lo toma casi como nosotros tomamos las afirmaciones cientificas, y conciben con el mismo modo de realidad "la palmera existe" y "el cielo existe". Una investigación filosófica se propone ser una reflexión posterior que tiene por objeto diferenciar esos modos de ser y mostrar su distinta realidad (o ilusión). Y resulta especialmente delicado captar con conceptos lo que originariamente es comprendido mediante simbolos.

En nuestra interpretación, ninguno de los modos de ser ha de negar al otro sino articularse con él, pues en caso contrario no dariamos cuenta de toda la complejidad de lo real. La libertad no puede destruir el mecanismo natural ni a la inversa, sino ponerse limites para dejarse mutuamente espacio ontológico y articularse entre sí como medios y fines. Es lo que por ejemplo Kant procura llevar a cabo en sus tres Criticas. Luego la libertad no puede pensarse como cosa al lado de las cosas del mundo y compitiendo con ellas, ni como cosa transcendente que no se articulara esencialmente con el mundo. sino como acción transcendental que es posible en cuanto que el modo de ser de la cosa es una visión 
especifica de la realidad, de la que son posible otras. Lo mismo ocurre con lo divino; nuestra interpretación de ello no puede anular la realldad de las cosas nt menos aún de la libertad, sino que ha de darlas sentido y amplitud ontológica, del mismo modo que la libertad humana procura dar un sentido a las cosas estableciendo un ámbito ontológico más abierto. No podemos encerrar, por tanto. lo divino en conceptos propios a los objetos ni a los sujetos.

Lo divino no es cosa, ni inmanente ni transcendente, y por tanto no es ni mundo ni otro mundo. Tampoco es sujeto, ni finito ni infinito, en consecuencia no es una persona providente y moral, sino que en lo divino hay tanto caos y noche como petición de orden, de comprensión y establecimiento de un orden. Por esto último, el ámbito de lo moral ha sido correctamente comprendido de forma simbólica como mandamientos de Dios; un orden que, sin embargo, nunca anula al caos originario ni a la lucha por la energia-materia. Pero no en el sentido de que lo originario fuera todo eso y después de ahi saliera el mundo, pues entonces lo habriamos pensado de forma transcendente y cósica mientras que a lo divino sólo podemos llegar en cuanto que descubrimos elementos originarios con los que se configuran el mundo y la realidad en general, y por tanto sólo partiendo de ésta como ya dada.

Al no ser cosa ni persona, no podemos atribuir a lo divino ni la unidad ni la pluralidad propia de ambos, ni la unidad o pluralidad de la heteronomia objetiva. ni tampoco las construidas por la autonomia del sujeto finito. En ninguno de esos dos sentidos podremos decir que lo divino sea uno (un Dios cosa o sujeto) o sean múltiples (dioses). Asi por ejemplo, toda persona humana habrá de ser consciente de su originariedad, de que es algo divino; en caso contrario andaria perdida por el mundo, en realidad ni pensaria ni actuaria sino que dejaria de ser. Pero no puede identificar lo divino con lo que él es de divino, pues todos los demás lo son de igual manera, y a la vez ninguno, dado que todos son también finitos: "¿Qué es esto que me traspasa de luz y golpea mi corazón sin herirlo? Me espanto y me enardezco. Me espanto, porque me siento distinto a ello; me enardezco, porque me siento semejante" (S. Agustín, Confesiones $11,9,1$ ). Lo originario no es algo uno en si (Platón, Plotino) que se manifieste de forma plural, ni es pura multiplicidad o una mera suma de todo, pues es también comunidad, lazo y 
sintesis, ni se agota en sus manifestaciones concretas objetivas pues es fuente de creatividad. Según su manifestación moral podriamos decir que es una unidad que se busca a si misma, pero que es también lucha, confrontación, diferencia, muerte, etc. donde se prueba la realidad de la multiplicidad, es decir, que las diferencias son necesarias, no mera ilusión sino reales, como real es el Individuo, el sujeto, su responsabilidad y su muerte, sin lo cual lo originario no seria. Y no una búsqueda de Alguien, sino de todos con o frente a todos para ser y saber, una fabulación en la que todos somos libro y poeta. Como ya dije, la unidad primaria a la que tiende la razón, sobre todo cuando filosofa, no es propiamente esa unidad objetiva, ya dada, que la razón exige en su uso teórico y que nos conduciria a la dialéctica. sino que, teniendo en cuenta la primacía de lo práctico, ha de ser comprendida como una tarea subjetiva de unidad sintética, donde los elementos se han de ir integrando sin confudirse, sino manteniendo su diferencia y autonomia originaria $y$, por tanto, inevitablemente y en alguna medida, el conflicto.

Por consiguiente, todo lo que se ha afirmado aqui sobre lo divino no se ha dicho como si estuviéramos predicándolo de una cosa o de un sujeto que se hallara más allá de las manifestaciones de lo originario, fundándolas substancialmente, o que al menos también pudiera ser transcendente a esas manifestaciones, pues de ello no tendriamos noticia. Sólo se puede afirmar su realidad en la medida en que se manifiesta y como se manifiesta, en cuanto elementos contrapuestos e integrantes de la sintesis de lo real. No se niega aqui la existencia de las experiencias religiosas, por ejemplo la de la revelación, sino que se ha procedido a una reinterpretación de las mismas por cuanto que ellas ya nos vienen necesariamente interpretadas en las diversas religiones y mitos, pues sin interpretación no habria ni siquiera experiencia. Es esa interpretación la que he discutido. La experiencia religiosa de lo divino no sólo no se ha negado, sino que se ha supuesto como dada.

Tampoco, como vimos, podemos reducir a una todas las demás manifestaciones de lo originario, o deducir las otras partiendo de una de ellas, porque se contraponen originariamente. Ni podemos pensarlas cósicamente separadas, pues sólo se nos manifiestan en esa contraposición, sintéticamente unidas. $Y$ en cuanto a su 
relación con lo no originario no es la de una identidad ni la de una diferencia cósica ni tampoco subjetiva. Siendo la causalidad la relación que se establece entre las cosas, lo originario no puede mantener esa misma relación con el mundo (creación), y menos aún consigo mismo (no es causa sui). Del mismo modo no podemos atribuirle una relación dialéctica (de poder) ni dialógica (de respeto) con los seres racionales como éstos mantienen entre sí.

Por último es fuente de posibilidad, realidad y necesidad, segün ya hemos ido viendo. Pero "fuente" es una metáfora. Todo lo que se pueda decir positivamente de lo divino habrá de ser matizado por esta "teologia negativa" que acabamos de ver, lo cual hace que nuestro hablar sobre ello sea más bien metafórico. Quien diga que entonces ese hablar carece de significado es que piensa que sólo podemos afirmar con fundamento el modo de ser de los objetos.

Además de mostrar y describir cómo se nos manifiesta lo originario, tan importante y quizás más es la tarea de mostrar cómo elaborarlo vivencialmente y hacer que llumine nuestra existencia. Pero esta es una cuestión que tendré que dejar aqui sólo indicada. 


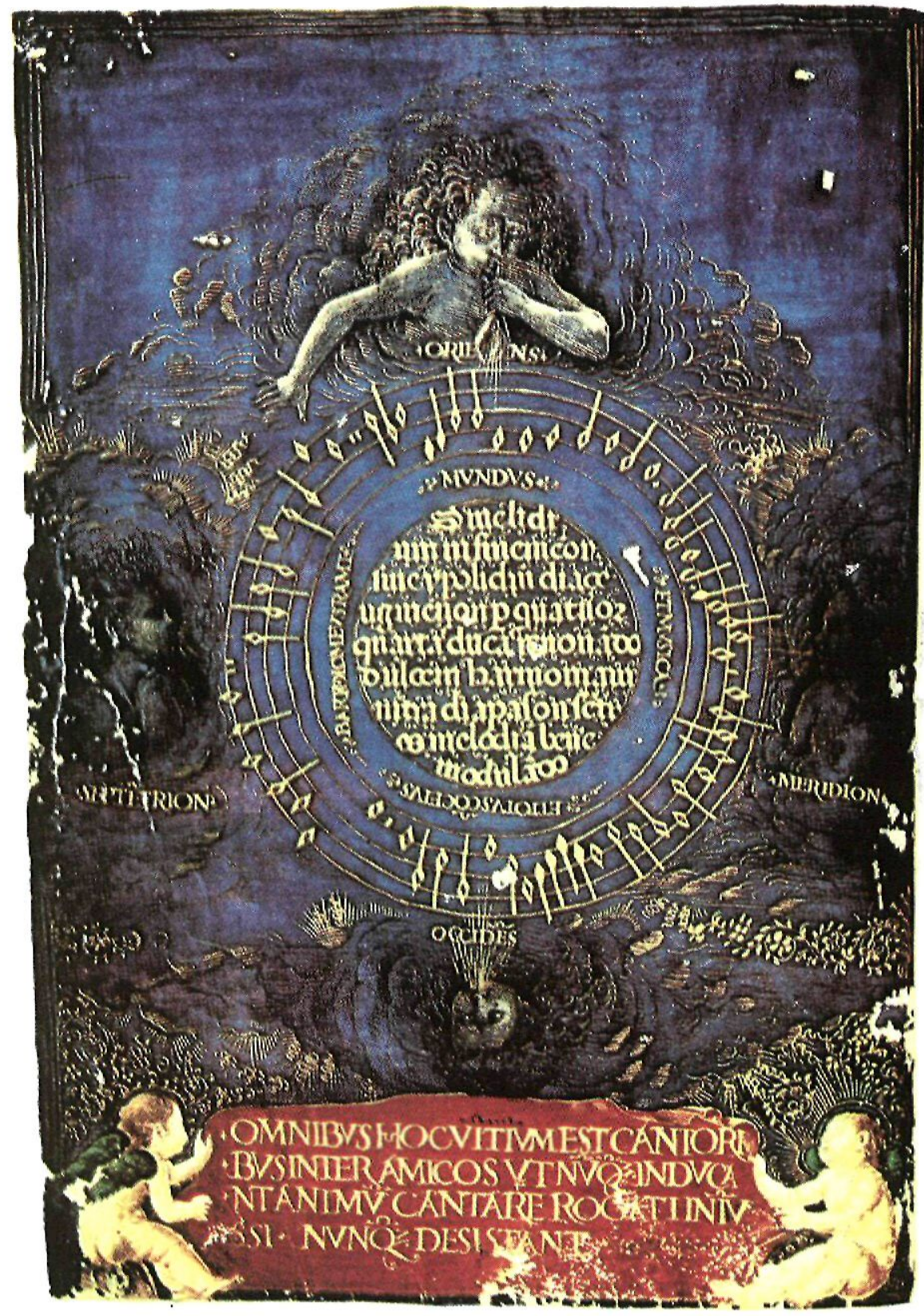

